\title{
Synergistic Approach of Graphene Oxide-Silver-Titanium Nanocomposite Film in Oral and Dental Studies: A New Paradigm of Infection Control in Dentistry
}

\author{
Sushil Kumar Upadhyay 1,*(D), Siddhartha Dan ${ }^{2}$ (D), Mohit Pant ${ }^{3(\mathbb{D})}$, Shaloo 4 (D) \\ 1 Department of Biotechnology, Maharishi Markandeshwar (Deemed to be University), Mullana-Ambala-133207 \\ (Haryana), India; sushil.upadhyay@mmumullana.org (S.K.U.); \\ 2 Department of Biotechnology, I.K. Gujral Punjab Technical University Jalandhar, Punjab; siddharthadan7@gmail.com \\ (S.D.); \\ 3 University Institute of Biotechnology, Chandigarh University, Mohali, Punjab, India; mohitpant97@ gmail.com (M.P.); \\ 4 Department of Pharmacology, KIET Group of Institutions, Ghaziabad, India \\ * Correspondence: upadhyay.k.sushil@gmail.com;
}

Scopus Author ID 57197228358

Received: 24.08.2020; Revised: 14.09.2020; Accepted: 14.09.2020; Published: 16.09.2020

\begin{abstract}
Nanoparticles have been used in numerous fields, various branches of science and engineering. These were used as a modification and to enhance the activity such as dentistry and oral investigation. The current survey uncovers that graphene oxide has been used to set up a variety of functionalized nanoparticles and progressed nanocomposites carriers. Graphene oxide shows potential in a variety of research examinations, for instance, tooth bleaching, antimicrobial activity, tooth erosion, teeth implants, toothaches, drug delivery at a specific site. All these usages of graphene oxide to biomedicine are excellent, and consoling Graphene oxide use in dental science has given amazing outcomes in antimicrobial activity, bone tissue building, regenerative dental, advancing dentistry biological materials, and in the treatment of oral cancer. The biocompatibilities of graphene oxide and its nanomaterial make them approaching units in bone regeneration, osseointegration, and cell multiplication. Furthermore, its antibiofilm and antiadhesion action encouraged researchers to formulate graphene oxide for biofilm. Nanostructures are utilized advancements or exploration of dentistry, and nanocomposite is employed for oral ailment preventive drugs, prostheses, and teeth implantation. Nanomaterials are further utilized as an oral liquid, mouth wash, or medication, forestalling and facilitating some oral malady and keep up oral wellbeing.
\end{abstract}

Keywords: graphene oxide; graphene oxide-silver-titanium nanoparticle; dentistry; nanocomposite film; nanotube; oral and dental infections.

(C) 2020 by the authors. This article is an open-access article distributed under the terms and conditions of the Creative Commons Attribution (CC BY) license (https://creativecommons.org/licenses/by/4.0/).

\section{Introduction}

Microorganisms are generally identified and found in periodontal contaminations and oral maladies. Colonies of oral microorganism are basically observed in the oral with a balance in a suitable microenvironment [1]. Unwanted reactions take place with respect to the change in equilibrium [2]. Huge quantities of microorganisms or contaminants are present inside the mouth cavity of an individual, in accordance with microorganisms as well as parasites, contaminants, and protozoa structure a bit of a normal microbiota [3]. Late information on a conventional oral microbiota, at any rate, has been limited to the bacteriome (in this way suggested as the microbiota) and very compelled to write about the mycobiota [4-6]. A late 
investigation explained the ongoing data on the preface of mold, which is a significant part of a solid and recipient mouth (oral) microbiota and hence not predecessor conditions analyzed here [7]. The microbiota has been gathered in exceptional detail, and phylogenesis information of microorganisms present in oral is amassed in databases focused on the hole of the oral [8]. A task assessment carried out by Human Microbiome assessed that microbiota piece of nine inside the mouth including the hard feeling of taste, keratinized gingiva, buccal mucosa, tonsils, subgingival plaque/supragingival plaque, spit, throat, and dorsum (i.e., an upper surface of the tongue) from around subjects 200 and has been detected family around 185-355, having an area with bacterial phylum 13-19 [9]. An evaluated sequence of 20-50 varieties and in 6 to 9 phylum was obtained from an individual who volunteers to give samples [10]. Notwithstanding, on the host some positive effect by a couple of infinitesimal life forms, there are minuscule living beings that sabotage therapeutic administrations, for instance, caries, gum malady (for example, Periodontitis and Gum disease) [11]. In the tooth connected with the significant negative impact is brought about by certain microscopic organisms are known for the significant reason for the negative effects that were connected with a tooth. Tooth pits on the outside of the teeth and some more are additionally caused by few microscopic organisms. The microscopic organisms, for example, have a place with Streptococcus genera and the species nonmutans streptococci, and $S$. sanguinis (intercourse the mouth and oral contaminations and sicknesses), Actinomyces as seen in dental plaque on the sound surface and the $S$. mutans began to develop on the tooth plaque [12]. As noticed outside of the teeth, $S$. mutans are more often than not distinguished microorganisms and huge etiological administrator of dentistry rot [13]. A causative administrator of contamination of the endocardium is these types of bacteria, as seen in many cases [14]. S. mutans create in the hole in the oral which implies a couple of exceptional mechanisms which include (acidogenicity) times period for induction of corrosion or resistance (acidurance) have a noteworthy role in the expansion in the basic contaminations alongside the capacity to convey extracellular sugar for example polysaccharides [ 15-17]. An ATP is produced by Gram-positive S. mutans with respect to anaerobic breath, and a noteworthy is a cariogenic infinitesimal life form [18]. A gigantic measure of natural acids delivered by $S$. mutans, and it elevates to decay the $\mathrm{pH}$ scope of the microenvironment of the hole of oral. Gram-negative anaerobic microorganisms Porphyromonas gingivalis and Fusobacteriumnucleatum, which are identified with genuine contamination of the gums, for example, periodontitis and disease in root trench [19-21].

\section{Carbon Nanotubes}

The carbon nanotubes (CNTs) have a unique mechanical and electrical characteristic. The carbon nanotubes strengthen the flexibility due to the covalent bond and the hexagonal orientation of the $\mathrm{C} 22 \mathrm{C}$. It has good thermal as well as good electrical semi-conductivity [22]. It has the best electrical as well as a mechanical characteristic like the efficiency of heat transmission, the stability of heat and density is lower, but the strength is higher so it can be used in the application of dental restoration and other types of applications. Needles of carbon nanotube are utilizing to bring agents (active) by Kanzius RF therapy, into cells (living) [23]. Geim and Novoselov in 2004, was first successfully made graphene [24]. A carbon allotrope consists of Sp2 hybridized carbon atoms, a densely folded sheet structure systematizes in a honeycomb crystalline forged [25]. It forms graphene, the thinnest material, without any spaces or structures dislocation, forming a uniform crystalline forged. This character yields the new physical characteristics of graphene [23]. Graphene increases the speed of light by acting 
electrons, mostly acting like electrons or neutrons [26]. Graphene is thus used in the converting of electricity from light using semiconducting materials, i.e., photovoltaics, biological devices, electrochemical capacitor, for disease diagnosis and its detection, and the construction of antimicrobial (bacterial) surfaces [27-30]. Graphene is thus used to treatment of types of biofilms bacteria [31]. For tooth decay by $S$. mutans and many serious infections of the gums, i.e., periodontitis, biofilm is most important for oral. Implants are capable of replacing missing teeth [32]. The biofilms are the most important thing because of their implant failures, and the biofilms potential caused by $S$. mutans is a nanocomposite of Graphene/zinc oxide [33]. The graphene-coated acrylic tooth is used for implantation due to its low cost, rupture strength, and lower-densities characteristics [33]. In the presence of nanocomposite of graphene/zinc oxide, anti-biofilm assays show biofilm deficiency [33]. In the making of porous scaffolds, it can utilize polycaprolactone/graphene [34]. Graphene oxide (GO) is a special characteristic physical as well as a chemical [35]. Graphene oxide comprises a monolayer of carbon sp2 atoms amid functional hydroxyl as well as epoxy groups on the top and in the perimeter carboxyl groups [36]. Such functional groups give active sites for metal and metals oxide hybridization and thus serve as a supporting surface for the growth of nanomaterials from metal and metal oxide [37]. Graphene's and its composites have been used for teeth implants, oral cancer treatment, good antimicrobial components, and imaging [38]. The use of graphene's and its nanomaterials as potential antimicrobial components has recently gained considerable interest in the area of Nano-medicine [39-42]. GO has also been investigated to demonstrate strong biocompatibility in comparison with other nanocomposites [43]. No research has yet investigated the anti-biofilm activity of nanocomposites of graphene/zinc oxide and nanocomposites of graphene/zinc oxide-coated dental surfaces on Streptococcus Mutans to the best of the authors knowledge [44]. This recent investigation aimed to test nanocomposites of graphene/zinc oxide's anti-biofilm as well as antimicrobial activity against $S$. mutans and the most important cause of decay infection and access to the coating of nanocomposites of graphene/zinc oxide in dentistry implant [44]. Graphene and GO are seen as promising nanocomposites to be applied in biological, clinical, and medical sciences. Up until this point, considering a couple of reports, it is noticed that graphene, GO, and diminished GO suspensions can control the development of Escherichiacoli, Streptococcusaureus, and Bacillus subtilis be that as it may, with insignificant cytotoxicity [45-49]. The impacts of GO on increasingly dentistry pathogens should be investigated. Due to its creative highlights, including antibacterial characteristics, realistic nanocomposites, including CNTs, fullerenes, and graphene, are viewed as novel and promising agents [50-52]. Graphene oxide nanosheets have better compound dependability and water solubility [53]. It's interesting and remarkable electrical conductivities, mechanical characteristics, enormous surface region, low, warm extension coefficient, and exceptionally high perspective proportion make it appealing for various potential applications in a wide range of areas [54-58]. Besides, graphene is a suitable substrate for biological/chemical reactions and is a biocompatible [59-60]. Like carbon nanotubes, graphene-based composites have gotten considerable attention for their potential in medical applications, including bacterial restraint, medicine transfer, and cancer therapy (photothermal) [61-63]. In this unique situation, graphene-related structures, for example, graphene nanoparticles, might be an important instrument in the clinical field, additionally because of their simple, economical, and adaptable creation process [56]. In past examinations, the antimicrobial action of graphene nanoparticles in opposition to both gram-negative Pseudomonas aeruginosa and gram-positive S. mutans microscopic organisms were explored, 
and their extremely low cytotoxicity was likewise shown through the in vivo strategy, i.e., Caenorhabditis elegans [64-65]. One of the key drawbacks of the wide utilization of graphene nanoparticles as an antimicrobial operator in dentistry applications, however, is the gray color and aggregation aptitude when spread in a colloidal suspension [66]. For this analysis, we used mainly traditional tooth decay bacteria, S. aureus, P. aeruginosa, and E. coli, for assessing the antibacterial activity of graphene oxide nanosheets in different concentrations [67-72]. The multifacial purpose, applications, and advantages of the graphene are depicted in Fig. 1.

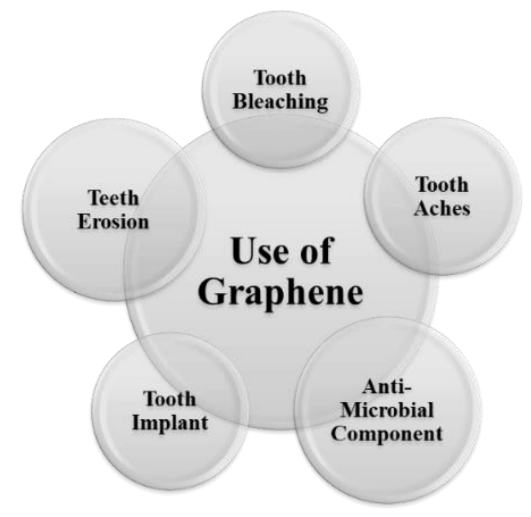

(a)

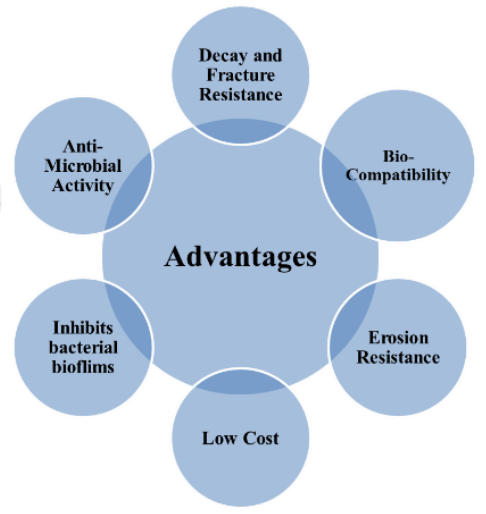

(b)

Figure 1. Applications (a) and advantages (b) of grapheme in biomedical sciences.

\section{Graphene Oxide and its Nanocomposites}

Bone morphogenetic proteins (BMPs) are the development elements, and it has multiuseful that exist to the group of development factor, for example, changing development factor $\beta$ (TGF- $\beta$ ). Bone morphogenetic proteins-2 (BMPs-2) has been initiated to assume an imperative job in the administration of odontoblasts separation, [94] with accepted BMPs flagging embroiling Smad1/5 [95] or Smad4 [96] as involving the c-Jun N-terminal kinase pathway [97]. The BMPs-2 can be utilized in enhanced medicinal remedial intervention and all the instances of abandoned bone, non-combination of bone with the break, expanding porosity in the bone, for example, osteoporosis and root trench abscission are appeared in Preclinical and clinical examination [98-101]. When graphene oxide is utilized as a carrier for remedial protein transmission, then graphene oxide goes about as a sufficient carrier for the controlled transmission of helpful proteins, similar to BMPs-2 [102]. Graphene oxide, while goes for the conveyance of bone morphogenetic protein-2 and substance $\mathrm{P}$, the double conveyance of BMPs-2 and substance $\mathrm{P}$ utilizing graphene oxide-Titanium produced new bone union on a Titanium-embedded site [103]. Kim et al. utilized a graphene-covered Titanium substrate as a hotspot for the conveyance of BMPs-2, osteogenesis is incited, and substance P, an immature microorganism enlistment administrator for in situ bone transformation. Graphene oxide was proficient at releasing bone morphogenetic proteins- 2 out of a persistent and steady way. The transfer of bone morphogenetic proteins- 2 and substance $\mathrm{P}$ utilizing graphene oxide helps the bone advancement on titanium embedded in the mouse skull (calvaria). The bone morphogenetic protein- 2 and substance $\mathrm{P}$ double conveyance could be utilized to redesign the osteointegration of dentistry or bone inserts [104].

\section{Antimicrobial and Cytotoxicity of Graphene Oxide and its Composites}

The meager graphene oxide film with silver (Ag) nanocomposites is stacked onto titanium (Ti) metallic surface by dint of lessening the metallic sheaths in the electric flow, so 
they structure flimsy cognizant metals covered on a cathode, for example, electroplating and bright decrease process. The amount of slender graphene oxide film and silver nanocomposites are controlled by explicit research facility apparatuses. The microbial counter rate and relative adherence movement of graphene oxide-silver-titanium are exceptionally unrestrained rather than strains of $S$. mutans and $P$. gingivalis. The substance that eliminates microorganisms by disinfectants, cleaning agents, or an anti-toxin, for example, bactericides component of GO$\mathrm{Ag}-\mathrm{Ti}$ is perceived by the microstructures, amount, position of the total layer in the right position and apoptosis (counting cell injury, maturing, and demise) and generally connected quality articulation of $S$. mutans and $P$. gingivalis. Henceforth, graphene oxide-silver-titanium (GO-Ag-Ti) nanocomposite is multiphase, could be viewed as a hint of something better over the horizon, demonstrating effective organic clinical items to hinder embed related diseases [105]. Minocycline hydrochloride (Mh), when usefully stacked in a hurry, altered the titanium surface. The Mh on graphene oxide-adjusted titanium delivered a moderate delivery and showed excellent enemy of bacterial rate opposite vigorous or facultative $S$. aureus (anaerobic microscopic organisms), E. coli (anaerobic microbes), and $S$. mutans (anaerobic microorganisms) alongside the agreeing synergistic impact of contact-slaughtering and discharge executing by graphene oxide just as $\mathrm{Mh}$. At the same time, Minocycline hydrochloride-graphene oxide-titanium (Mh-GO-Ti) demonstrated brilliant cytological similarity, which could animate the Human gingival fibroblast cells expansion in vitro (In a test tube). On the other hand, the results of co-culture suggest that Human gingival fibroblast cells on Mh-GO-Ti demonstrated magnificent cell bond and maximal cell surface inclusion, which are vital for embed in clinical application rebuilding because of the essence of $S$. aureus [106]. As graphene oxide is advanced from graphene, it presents a few oxygen animal groups which permit functionalization and combination with the biomaterials that can be accomplished through compound peeling from graphite. The graphene oxide-based substrate demonstrated Dental mash immature microorganism (DPSC) linkage, enlargement, and multiplication expanded numerous article qualities that are upregulated in mineral-creating cells. These examinations bring new conditions for the utilization of graphene oxide alone or in relationship to improve the organic movement of dentistry items and ayont this [107]. The examination acknowledges critical data about the correspondence of human dental follicle cells (hDFCs) undifferentiated living beings with graphene-based nanoparticles. $\mathrm{N}$-doped graphene reduces the achievability of the cell at $40 \mathrm{~g} / \mathrm{ml}$ and changes the mitochondria film potential and cytoskeleton (is comprised of microtubules, actin fibers) by mechanical effects. It shows a better than average prosperity profile at $4 \mathrm{~g} / \mathrm{ml}$, nearby high cell hostile to oxidant security. GO shows extraordinary results similar to low degrees of cytological harmfulness and mitochondria incited hurt, in human dental follicle cells (stem cell). Strangely with these two items, the warm lessened GO shows extended cytological harmfulness. Considering our examination opens the opportunity of future use of GO and nitrogen-doped graphene as fillers in various dentistry nanoparticles items [108]. Silver nanoparticles were reliably kept on the surfaces of diminished graphene sheets by a clear anyway, especially effective technique. Silver nanoparticles supported on graphene were viewed as especially dissipated with little gathering. Diminished graphene-silver nanoparticle (R-GNs/Ag) composites indicated updated antimicrobial activities toward oral microorganisms differentiated, and unadulterated silver nanoparticles and one of a kind reduced graphene nanoparticle, which may be credited to the better dispersibility of silver nanoparticles on graphene surfaces. Regardless, the counter microbial activity of a decreased graphene-silver nanoparticle can be affected by various components. As needs are, 
further work on the particular antibacterial segment of reduced graphene-silver is required, which may help us with improving the antibacterial effects of decreased graphene-silver against oral microorganisms [109]. Hydroxyapatite/graphene oxide nanocomposites are used for orthopedic, medication move, and dental explores and treatment. Hydroxyapatite/graphene oxide shows a fabulous natural similarity [110].

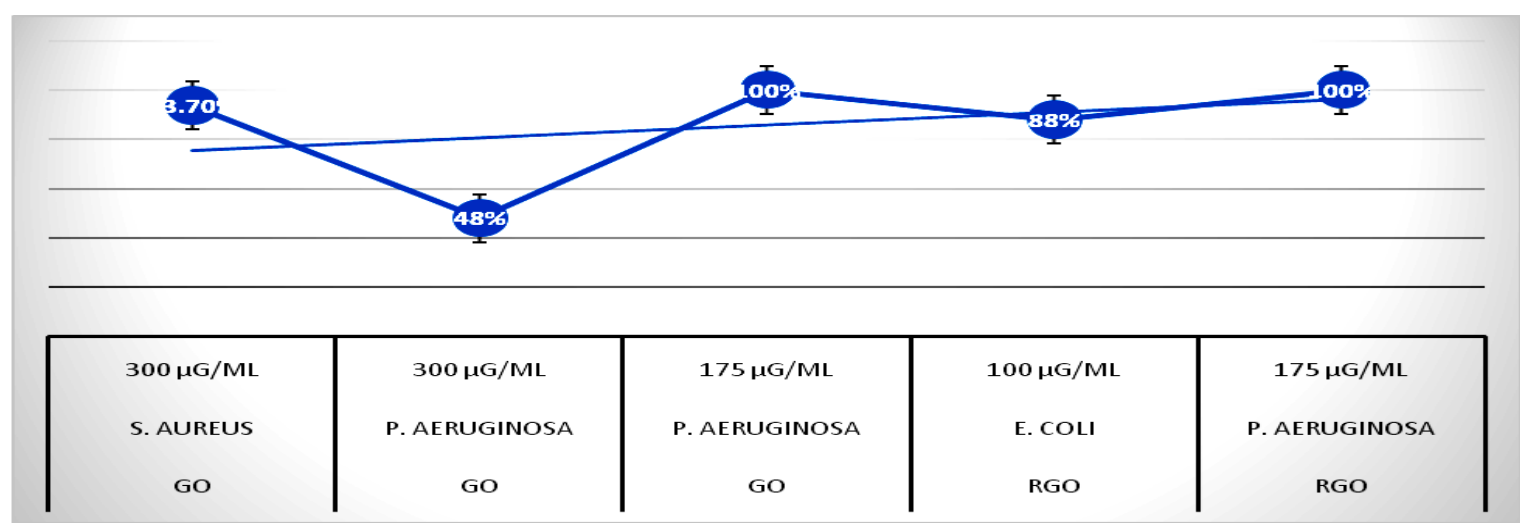

Figure 2. The growth curve of bacteria (S. aureus, P. aeruginosa, and E. coli) at different concentrations graphene family for maximum growth inhibition.

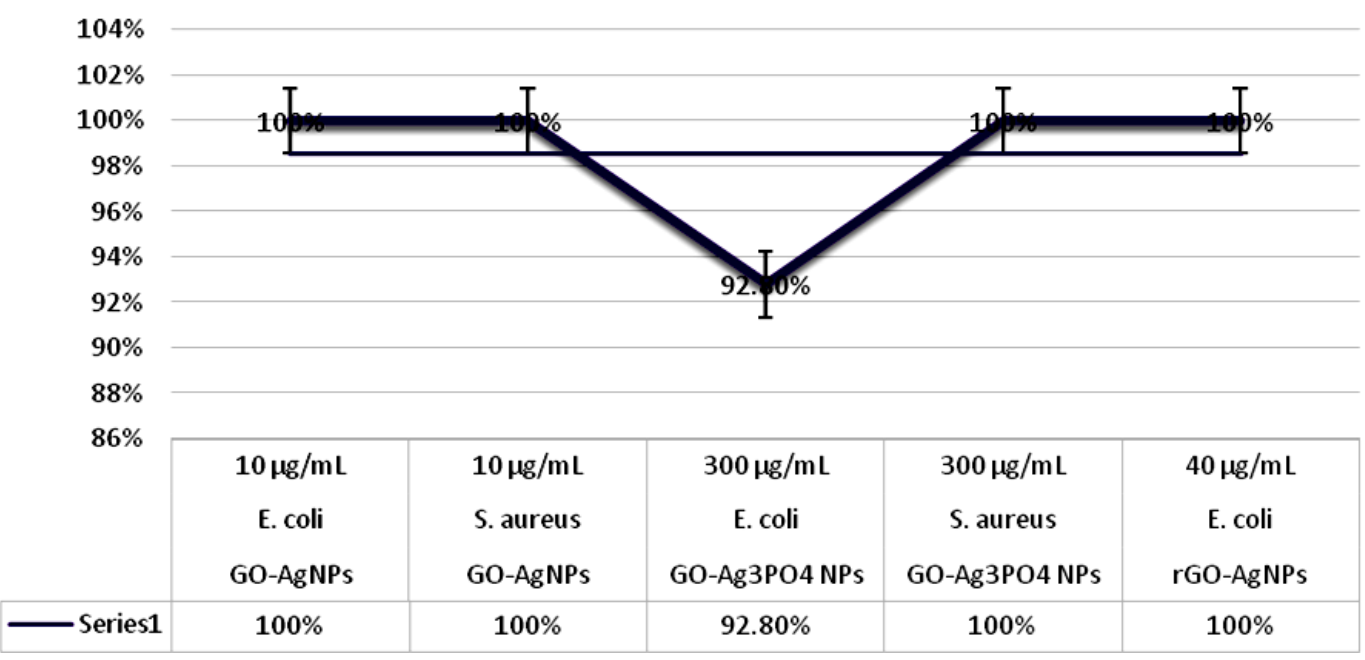

Figure 3. The growth curve in bacteria (S. aureus, and E. coli) for functionalized silver NPs at different concentrations for maximum growth inhibition.

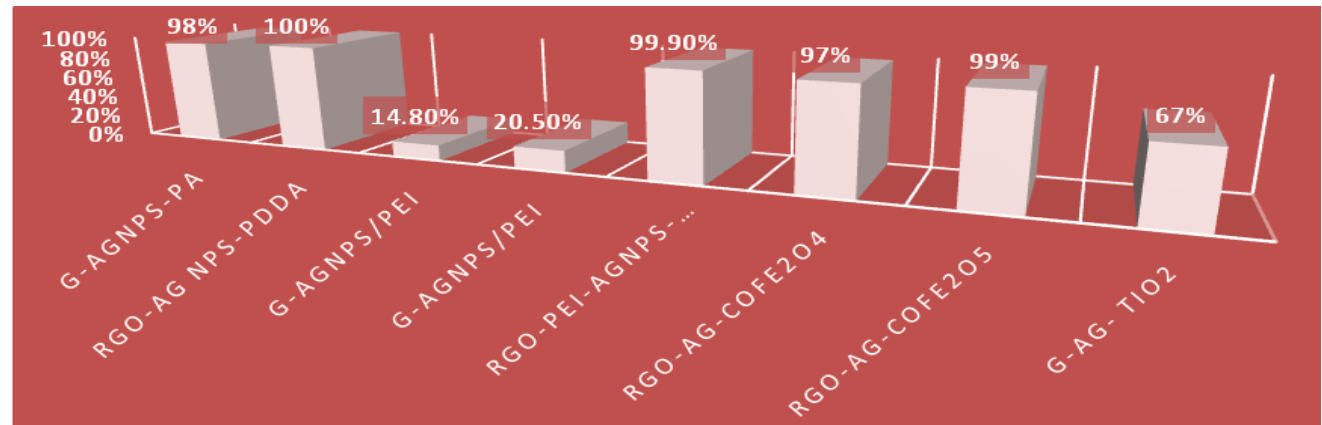

Figure 4. The growth curve in bacteria (G-AgNPs/PEI and rGO-Ag-CoFe2O5 are treated in S. aureus, and E. coli) for multicomponent composite functionalization at the different concentration for maximum growth inhibition.

Reports of the bacteria's, i.e., Gram-positive $S$. aureus, Gram-Negative P. aeruginosa, and Gram-negative E. coli; growth curve for the families of graphene [73-76], the functionalized Ag nanoparticles [77-79], photocatalytic functionalized [81-83], functionalized metals oxides [84-87] and multicomponent reactions-based modified [73, 88-91] at a different 
type of concentration and also the maximum growth inhibition has been measured for all these three bacteria (Figs. 2-6). The growth curve investigates of E. coli and $S$. aureus for multicomponent composite functionalization GO-Ag NPS-PAA at concentrations 24 and N/A and the study of E. coli for GO-Ag NPs-PDA at concentration $25 \mu \mathrm{g} / \mathrm{ml}$ [92-93]. For GO-Ag NPS-PAA, the maximum growth inhibition of 9.9/11.4mm and for GO-Ag NPs-PDA and the maximum growth inhibition of $23.7 \mathrm{~mm}[73,93]$ was recorded.

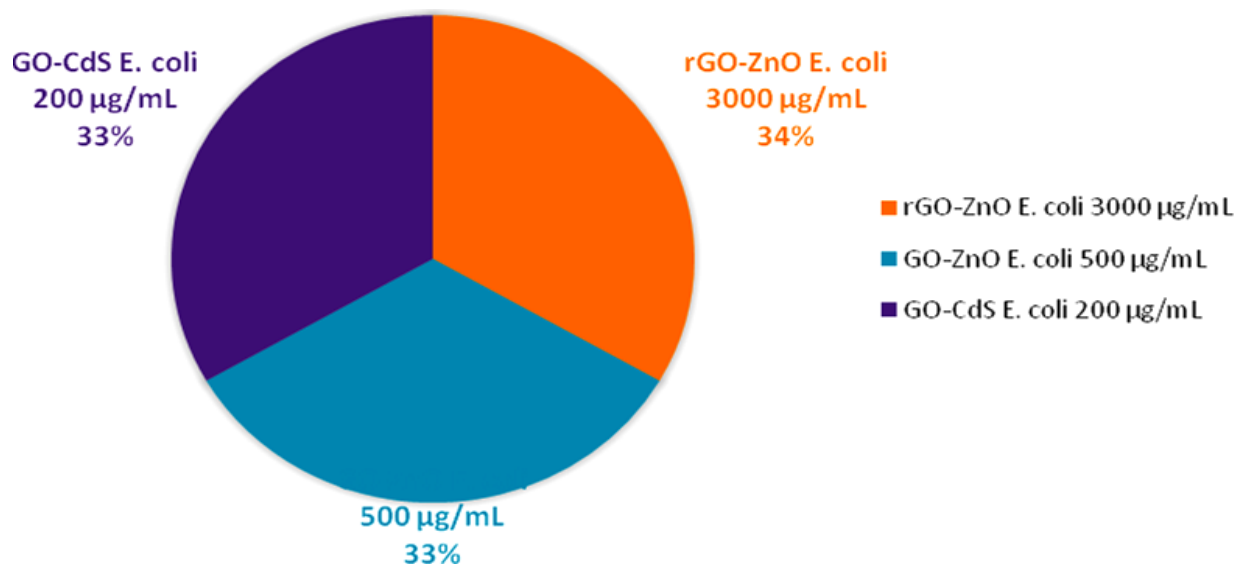

Figure 5. The growth curve in bacteria (E. coli) for photocatalytic functionalization at different concentrations and maximum growth inhibition.

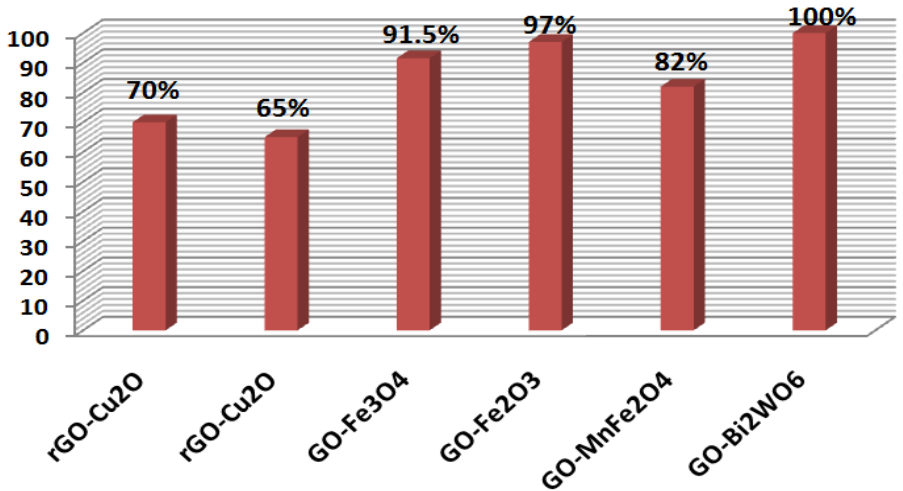

Figure 6. The growth curve in bacteria (S. aureus, E. coli, and mixed culture) for functionalization with other metal ions/oxides at different concentrations and maximum growth inhibition.

\section{Oral Cancer}

Using the electrochemical procedure, we can recognize the biomarker for oral cancer. The serum level of cytokeratin fragment-21-1 (Cyfra-21-1) was measured to determine the cells whether they are associated with epithelial cell cancers or not. Nanoparticles that contain cerium oxide nanotubes along with $\mathrm{GO}\left(\mathrm{ncCeO}_{2}-\mathrm{RGO}\right)$ are used in this field. In situ reduction of GO is done to get the nanoparticles of cerium oxide and reduced GO. The reaction is carried out in the presence of hydrazine hydrate. Reduced GO is highly conductive, and this property helps to make it a perfect material to form nanoparticles and hence can be used electrochemically along with cerium oxide for the detection of cancers. The cerium oxide nanotubes provide a large surface area to volume ratio for additional surface adjustment by anti-Cyfra-21-1, which results in the synergistic property of the nanoparticles. This immune sensor shows the particular disclosure of cytokeratin piece $21-1$ from $0.625 \mathrm{pg} \mathrm{ml}^{-1}$ to $15 \mathrm{ng} \mathrm{ml}^{-}$ ${ }^{1}$, most decreased affirmation limit $0.625 \mathrm{pg} \mathrm{ml}^{-1}$ with all-inclusive affectability $14.54 \mu \mathrm{A} \mathrm{ng}^{-1}$ $\mathrm{ml} \mathrm{cm}{ }^{-2}$. Moreover, this immune sensor can check the cytokeratin section 21-1 in saliva tests as recorded by the unprecedented reaction with the spiked models [111]. 
This is basic criteria for the use of graphene oxide in the treatment of oral malignancy as it was declared that the treatment of graphene oxide limited Wnt signaling and Notch-driven signaling, and furthermore, signal transducer and activator of transcription proteins 1/3 (STATs) signaling and the atomic factor erythroid 2-related factor 2 (NRF2)- subordinate cell reinforcement reaction, while the little effect was seen on changing development factor$\beta /$ SMAD-signaling [112]. Regardless, several investigations in this field have been represented. Usage of graphene oxide in the treatment oral malignant growth has been represented by Kumar et al. [113], who explored the production of a non-obtrusive, without a mark, and capable biosensing stage for the disclosure of the biomarker CYFRA-21-1 in oral malignant growth. They proposed using a zirconium oxides-decrease graphene oxide nanomaterial for looking at the effect of zirconium oxides nanoparticles; additionally, the movement of neutralizer antigen acting master trades in the presentation of this immunosensor. Thusly, more spotlight on such uses could give positive results in the treatment of oral threat and malignancy [113].

We can apply nitrogen-doped graphene oxide in anticancer prescription transport and performed both in vivo and in vitro endeavors. In their appraisal, the impacts of ligand thickness on amazing tumors focusing on the limit of nitrogen-doped graphene oxide were assessed utilizing folate as a model ligand. KB cells demonstrated that developing ligand thickness broadened the cell take-up of nitrogen-doped graphene oxide genuinely, yet in vivo data of tumor assortment of nitrogen-doped graphene oxide exhibited a low fundamental ligand thickness. The higher tumor assortment of nitrogen-doped graphene oxide by ligand conjugation over the essential concentrate also realizes better photothermal tumor evacuation in vivo. Notwithstanding in vitro results, they ensure the powerful usage of nitrogen-doped graphene oxide as a drug transport device for disease treatment [114].

Platinum (Pt) stacked graphene quantum speck composite (GPt), changed through polyethylene glycol (PEG), can upgrade the oral threat (oral squamous cell carcinoma) chemotherapeutic effectuality. Platinum stacked graphene quantum dab composite could upgrade the repression in the Synthesis period of the cell cycle and lead to cell apoptosis. It possibly brings the platinum swelling up in both normoxia and hypoxia (province of oxygen commonality) conditions inside cells. The in vivo yield offered by Platinum stacked graphene quantum speck composite uncovered that platinum stacked graphene quantum dab composite could be a model for original composite for malignancy healing treatment by coordinating the pharmacopeia of the medication for higher tumefaction accumulation and marginally limiting fundamental poisonousness. Subsequently, the consolidated nanoparticle conveyance is relied upon to have expanded clinical use in the blink of an eye treatment of malignant growth. [115]. Further, the use of biocompatible Graphene oxide alongside azo-sweet-smelling compound and strong Polyvinyl liquor (PVA) hydrogels encompassed by curcumin GO-N=N-GO/PVA were seen as sheltered in the stomach and hence expanding the colon-focusing on ability and abiding time inside the colon. Accordingly, these hydrogels composites are relied upon to treat colorectal disease with high profitability and lower harmfulness [116].

\section{Tooth Erosion}

So, multi-walled carbon nanotube with graphene oxide ties with nano-hydroxyapatite seemed to outline a cautious layer for dentistry against erosive methodology. Dentistry treatment with nano-hydroxyapatite achieved extended part carbonate in light of a possible relationship with counterfeit salivation. Acidulated phosphate fluoride gel treatment identified 
with multi-walled carbon nanotube with graphene oxides or nano-hydroxyapatite/multi-walled carbon nanotube with graphene oxides covering reduced the band region identified with the normal material. This could have happened by surrounding an additional limit, which lessened the regular framework introduction. SEM micrographs showed that after erosive cycling, the dentin compensated with acidulated phosphate fluoride and secured with hydroxyapatite/multiwalled carbon nanotube with graphene oxides held some degree of spread. This suggests by talking with the dentin, the covering falsely connections to dentin, subsequently making sure about it during deterioration cycles. Nano-hydroxyapatite, multi-walled carbon nanotube with graphene oxides and nano-hydroxyapatite/multi-walled carbon nanotube with graphene oxides-secured acidulated phosphate fluoride dentin extended the carbonate/phosphate extent and ensured about the dentistry against erosive masters (electrochemical impedance spectroscopy assessment). These revelations showed that the unfaltering quality of nanohydroxyapatite and multi-walled carbon nanotube with graphene oxides following erosive cycling was likely associated with the headway of a destructive safe surface film, and the previous utilization of fluoride invigorated this correspondence (explored by electrochemical impedance spectroscopy). We recognize somewhat the invalid theory attempted here that the biggest differences were in normal substance and morphology of dentistry for each inspected item [117].

\section{Tooth Aches}

In the diagram, the amalgamation of the outstandingly specific and delicate electrochemical recognizing of paracetamol using nanosized cerium oxide nanoparticles is adorned with diminished graphene nanocomposite modified anode was represented. The PM sensor shows a wide straight extent of $0.05-0.600 \mu \mathrm{M}$ with identification just as affectability limit $(\mathrm{S} / \mathrm{N}=3) 0.0092 \mu \mathrm{M}$ and $276 \mu \mathrm{A} \mu \mathrm{M}^{-1} \mathrm{~cm}^{-2}$, independently. The nanosized cerium oxide with diminished graphene oxide nanocomposite is found to have incredible selectivity, affectability, quality, and reusability with the high electrocatalytic development toward paracetamol. The proposed methodology for explicit acknowledgment of paracetamol in different examples tests with incredible recoveries can be adequately applied here. Such an investigation will point of fact, prepare for the disclosure of bleeding-edge paracetamol sensors that could be inserted for industrious seeing of paracetamol run through different body-liquids [118].

\section{Tooth Bleaching}

We picked four sorts of recoloring (D\&C Red No.17, D\&C Red No.34, D\&C Red No.36, and D\&C Orange No. 4), 3 sorts of lighting up (hydrogen peroxide alone, hydrogen peroxide cobalt-tetra phenyl porphyrin, and hydrogen peroxide cobalt-tetraphenyl porphyrin/decreased graphene oxide) and 3 separate light sources (not photo lit up, photo lit with $245 \mathrm{~nm}$, and photo lit with $310 \mathrm{~nm}$ ), on account of the disclosures of this investigation, cobalt-tetra phenyl porphyrin, and Hydrogen peroxide cobalt- tetraphenyl porphyrin/diminished graphene oxide nanocomposite was used as a gadget for dental whitening, and it basically extended the blurring viability of hydrogen peroxide [119]. 


\section{Membranes in Dental}

To improve the general capacity of guided bone regeneration (GBR) layers in an oral medical procedure (surgery), the expansion of graphene must improve the capacity of the film to keep delicate tissue cells from penetrating the developing bone [120]. The expansion of graphene must do this while additionally holding fast to the five standards underlines by Scantlebury: biocompatibility, space-production, tissue joining, and clinical sensibility [121]. While advancing collagen films with graphene oxide and testing its impact on human gingival fibroblasts, the nearness of graphene oxide on collagen layers brought about lower deformability, decreased hydration, higher firmness, and expanded unpleasantness in contrast with non-covered layers. Following three days of culture and the encouraged attachment of proteins to the film, it was found that these progressions made by the graphene oxide on collagen evaded any sort of provocative reaction and generally preferred the multiplication of human gingival fibroblasts. The investigations performed with graphene oxide on collagen films were finished utilizing two distinct measures of graphene oxide: one at $2 \mu \mathrm{gml}^{-1}$ and one at $10 \mu \mathrm{gml}^{-1}$, both making the equivalent previously mentioned valuable outcomes to human gingival fibroblasts [122]. At the point when applied to human dental pulp stem cells, graphene oxide -covering on collagen films is found to render cells incapable of entering into the layer, while the more focused graphene oxide covering brings about the development of a thicker cell layer. These disclosures are made through hematoxylin-eosin recoloring. Graphene oxide covering of collagen layers is likewise resolved to advance the procedure of osteoblastic separation, to be perfect with cell suitability in a portion subordinate way, and to diminish irritation $[122,123]$. Once more, even though it appears to be truly conceivable that these graphene oxides covered films can be utilized to improve or supplant the current guided bone regeneration layers utilized in dental, various conditions, have and ecological variables ought to be considered before arriving at an authoritative resolution on the use of graphene in layers.

\section{Inhibition of Bacteria Biofilms}

Microscopic organisms' biofilms accept imperative employment in dentistry pathogenic frameworks because of their capacity to endure through different standard antibacterial administrators. Thusly, it is pivotal to find productive techniques to quell the creation of biofilms. Starting late, Zisheng Tan and his partners confirmed that graphene oxide nanosheets could productively subdue $S$. mutans biofilm game plan over a wide extent of obsessions during the beginning events of the bacterial biofilm advancement $(0-4 \mathrm{~h})$. Peculiarly, because of creating biofilms (six hours), graphene oxide had only an irrelevant impact [124]. They found that intertwining graphene oxide to a making film could limit the connection and activity of bacterial cells during the starting season of the biofilm course of action, and graphene oxide was stunning in slaughtering the $S$. mutans organisms. Additionally, the sheet-like structure of graphene oxide could conjugate with cells to shape a representing inorganic utilitarian layer, which influenced the capacity of the minute living beings to transmit extracellular polymeric substance. This is basic as extracellular polymeric substance accepts a basic protective activity in the association approach and restriction against antimicrobial experts. The low extracellular polymeric substance will instigate less troublesome destruction of the encircling movies. Wretchedly, inferable from the bountiful extracellular polymeric substance released, organisms in create biofilms are less tricky to the proximity of graphene oxide. Finally, the obtained delayed consequences of their work showed that graphene oxide 
nanosheets are astounding in hindering and compensating oral contaminations by encroaching with the game plan of bacterial biofilms [124].

\section{Implants}

Ti embeds are starting at now saw as the best exchange for the regular tooth in light of the fact that how they have positive biocompatibility, are strong and obvious. Nevertheless, titanium's naturally dormant quality leaves it feeble to impelling the improvement of strong tissue. This can make the insert miss the marks making titanium implants the best other option, yet open to advance $[125,126]$. The structure of an endosseous implant is made out of a device that is put on the bone, close by a projection screwed to the most noteworthy purpose of the establishment and the upper prosthesis, as ousted. Considering the recently referenced preferred position of graphene oxide - covering concerning human dental mash immature microorganisms, graphene oxide-Titanium embeds were made. Each way that the additions were made, they demonstrated that graphene oxide-covering of Titanium embeds makes, for the most part, improved favorable position over titanium inserts alone. These improvements are generally concerning cell osteogenic division, yet furthermore with the biocompatibility and cell development of the supplements too [127-129]. Graphene oxide-covering of titanium embeds has also been exhibited to make antibacterial properties on these supplements, most sufficiently when the graphene oxide covering is functionalized with antibacterial substances, for instance, silver nanoparticles and against contamination operators. Exactly when gotten together with the serum poison minocycline hydrochloride, the graphene oxide-covering improves the antibacterial activity against facultative anaerobic or overwhelming infinitesimal living beings due to the synergic effect of minocycline release butchering and graphene oxide contact-killing. Graphene oxide-silver covering on Ti has been exhibited to be helpful against Porphyromonasgingivalis and Streptococcus mutans. It would then have the option to be found that the graphene oxide - covering with hostile to contamination specialists or silver on titanium embeds improves the antibacterial attributes of the titanium embeds, shielding infections from developing in light of the implant being used in the patient [127,130,131].

Despite the fact that graphene oxide-covering with these particular nanocomposites have antibacterial effects against practically identical and different sorts of infinitesimal creatures depending whereupon is used, it will, in general, be settled that a graphene oxide covering of titanium embeds with one of these nanocomposites would be an improvement to the standard Titanium insert. These improvements may have the alternative to broaden when one considers the limit of periodontal tendon foundational microorganisms to fill in as a choice as opposed to bone marrow mesenchymal stem cells that were referenced previously. Periodontal tendon immature microorganisms energize the use of graphene oxide as a strong canvas on which to shape the structure and limit of these periodontal tendon undifferentiated cells. Periodontal tendon foundational microorganisms seeded onto graphene oxide-secured stages show a higher extension rate than on graphene oxide alone, and a Sodium-Titanium substrate is useful as well. Wrapped up from this is the way that a mix of periodontal tendon foundational microorganisms, graphene oxide, and Sodium-Titanium can make many remembered overhauls and points of interest for the field of regenerative dentistry [132]. Thus, likewise with the rest of graphene and graphene-based nanomaterials'applications in dentistry, the reaching out of these points of interest from systems to embed in a regenerative manner ought to be furthermore perused and gone after for undeniable favorable circumstances to result [127]. Graphene has various possible focal points to embed in dentistry; regardless, the 
nanoparticles that it is joined with and the biological components of each patient's oral gap must be considered for every circumstance before any further measure is taken.

\section{Applications of Graphene and its Composite Nanoparticle}

Nanoparticles have been used in numerous fields used in various branches of science and engineering. Basically, used as a modification and to enhance the activity such as electrical, optical, and biological. Nanotechnology is widely used in our day to day life, including its use in medicine. Using nanotechnology, we can analyze and also can manipulate atoms, chemical bonds, and molecules present in different compounds. Various types of nanoparticles are used in nano dentistry. Nanomaterials are used in toothpaste and other rinsing solutions for better oral healthcare services, which will become less stressful for dental surgeons. The nanomaterials have been used in the dental filling, polishing of the enamel surface to prevent caries, and as implant materials in dentistry also that are more effective than the conventional materials. Some of the nanoparticle act as an antimicrobial agent, thus prevent bacterial growth. Nanodentistry attracts patients towards dentistry since; it will be cost-effective, timesaving, and prevent the patient from mental trauma. In this study, below are some of the particles used. Graphene and its composites are versatile materials that have various characteristic features such as large surface area, high mechanical properties and can be transferred or deposited onto different substrates. The combination of these composite materials with different compositions, structures, and properties can result in composites with tailored physical and chemical characteristics and modified mechanical properties or bioactivity. Due to the enhanced capabilities, composites are widely used in dentistry and other biomedical areas.

Table 1. Applications and advantages of graphene oxide and composite nanoparticles.

\begin{tabular}{l} 
Nanoparticles \\
\hline GO and rGO
\end{tabular}

\section{Functions}

\begin{tabular}{l|l} 
GO and rGO & Teeth implants, a biomarker in oral cancers, good antimicrobial activity, hydrophobic material,
\end{tabular} cause oxidative damage, cytotoxic nature, induced the least amount of damage to the dental follicle, decrease dental pathogens, acts as an adsorbing agent, upregulate expression of betacatenin protein and activate catenin/wnt signaling pathway, increase the degree of proliferation and differentiation of cultured cells and led to an acceleration of bone formation, graphene form derivatives with titanium and utilized in dental implants, bone regeneration, resins, cement and adhesives, tooth whitening procedure, etc.

\begin{tabular}{|c|c|}
\hline GO-AgNPs & Antibacterial \\
\hline $\mathrm{GO}-\mathrm{Ag}_{3} \mathrm{PO}_{4} \mathrm{NPs}$ & Acts as biomaterials, inhibit corrosion, antibacterial agent, light-sensitive agent \\
\hline rGO-AgNPs & Action is faster than GO, increase activity of GO NPs \\
\hline rGO-ZnO & $\begin{array}{l}\text { Oral cancer biomarker with nCeO2-rGO and as reinforcement materials to commercial glass- } \\
\text { ionomers cements (GIC) }\end{array}$ \\
\hline $\mathrm{GO}-\mathrm{ZnO}$ & $\begin{array}{l}\text { Graphene/zinc oxide nanocomposite (GZNC) forms a biofilm, teeth, fracture-resistant and low- } \\
\text { density property that is suitable for implantation. }\end{array}$ \\
\hline GO-CdS & $\begin{array}{l}\text { The CdS/RGO composite material can be used as a gas sensor for } \mathrm{CO}_{2} \text { based on its } \\
\text { electrocatalytic behavior. }\end{array}$ \\
\hline $\mathrm{rGO}-\mathrm{Cu}_{2} \mathrm{O}$ & Antibacterial and $\mathrm{CO}_{2}$ reduction without the need for a noble-metal co-catalyst. \\
\hline $\mathrm{GO}_{-} \mathrm{Fe}_{3} \mathrm{O}_{4}$ & Antibacterial, Photosensitive \\
\hline $\mathrm{GO}-\mathrm{Fe}_{2} \mathrm{O}_{3}$ & $\begin{array}{l}\text { GO-Fe } 2 \mathrm{O} 3 \text { hybrid material can act as an efficient heterogeneous catalyst for the degradation of } \\
\text { organic contaminants, which may provide insight into the design and development of high- } \\
\text { efficiency visible-light photocatalyst for water treatment. }\end{array}$ \\
\hline $\mathrm{GO}-\mathrm{MnFe}_{2} \mathrm{O}_{4}$ & $\begin{array}{l}\text { Use for adsorptive removal of } \mathrm{Pb} 2+\text { ions from the aqueous medium, low-cost adsorbents for fast } \\
\text { and effective removal of arsenic from water, a recyclable catalyst for the reduction of p- } \\
\text { nitrophenol }\end{array}$ \\
\hline $\mathrm{GO}_{-\mathrm{Bi}_{2} \mathrm{WO}_{6}}$ & Photocatalytic activity \\
\hline G-AgNPs-PA & Antibacterial and antioxidant \\
\hline rGO-Ag NPs-PDDA & $\begin{array}{l}\text { Antibacterial widely used in various applications such as wastewater treatment plants and } \\
\text { various biological and medical applications }\end{array}$ \\
\hline G-AgNPs/PEI & $\begin{array}{l}\text { Antibacterial, cell culture for weakly anchoring cells, a cationic polymer, carbon dioxide capture } \\
\text { and separation }\end{array}$ \\
\hline rGO-PEI-AgNPs-Fe $2 \mathrm{O}_{3}$ & Antibacterial \\
\hline rGO-Ag-CoFe $2 \mathrm{O}_{4}$ & bacteria \\
\hline
\end{tabular}




\begin{tabular}{|c|c|}
\hline Nanoparticles & Functions \\
\hline rGO-Ag-CoFe ${ }_{2} \mathrm{O}_{5}$ & Anticancer, antibacterial \\
\hline GO-Ag NPS-PAA & $\begin{array}{l}\text { Antimicrobial prop enhance, disposable diapers, ion exchange resins, adhesives, detergents, } \\
\text { acrylics, }\end{array}$ \\
\hline GO-Ag NPs-PDA & $\begin{array}{l}\text { Wound dressing application, antimicrobial, and polymer, coating material, adsorbents coating in } \\
\text { biomedical science }\end{array}$ \\
\hline GO-Ag-Ti & Antibacterial, inhibit implant-related infections and electrophoretic deposition, \\
\hline hydrazine hydrate & Acts as a reducing agent, oxygen scavenger, source of drug hydralazine in Anti TB, as fuel \\
\hline polyethylene glycol & Polymer, making dental material, fillings, biofilm formation or implants \\
\hline $\mathrm{ncCeO}_{2}-\mathrm{RGO}$ & $\begin{array}{l}\text { Great selectivity, affectability, strength, and reusability with a high electrocatalytic movement } \\
\text { toward paracetamol and sensitive electrochemical sensor, protect human dental stem }\end{array}$ \\
\hline Hydroxyapatite/GO NPs & $\begin{array}{l}\text { Orthopedic, dental research \& treatment has biological compatibility, defensive layers for } \\
\text { dentistry against erosive procedures, fillers in dental or orthopedic applications too }\end{array}$ \\
\hline $\begin{array}{l}\text { Platinum (Pt) loaded- } \\
\text { graphene quantum dot } \\
\text { composite, modified via } \\
\text { polyethylene glycol }\end{array}$ & $\begin{array}{l}\text { Enhance the oral malignancy (oral squamous cell carcinoma) chemotherapeutic efficaciousness } \\
\text { enhance the confinement in the Synthesis phase of the cell cycle and lead to cell apoptosis, } \\
\text { potentially raises the platinum inflation in both normoxia and hypoxia (state of Oxygen } \\
\text { normalcy) conditions inside cells, cancer remedial treatment therapy, treatment of cancer. } \\
\text { Catalytic ozonation, dental restorations and provide strengths and stiffness }\end{array}$ \\
\hline $\mathrm{GO}-\mathrm{N}=\mathrm{N}-\mathrm{GO} / \mathrm{PVA}$ & $\begin{array}{l}\text { Increase colon targeting capability \& dwelling time inside the colon and hence colorectal cancer. } \\
\text { Filling, antibacterial }\end{array}$ \\
\hline Paracetamol & Toothaches, fever, aches in dentistry \\
\hline $\begin{array}{l}\text { Hydrogen peroxide } \\
\text { cobalt }\end{array}$ & Bleaching and antiseptic \\
\hline tetra phenyl porphyrin & Electronics, production of singlet oxygen \\
\hline $\begin{array}{l}\text { anti-toxin minocycline } \\
\text { hydrochloride }\end{array}$ & Tetracycline antibiotic used to treat bacterial infections \\
\hline $\begin{array}{l}\text { Minocycline } \\
\text { hydrochloride-GO-Ti }\end{array}$ & Antibacterial, stimulate the human gingival fibroblast cells proliferation in vitro \\
\hline $\begin{array}{l}\text { cerium oxide nanocubes } \\
\text { with rGO }\end{array}$ & $\begin{array}{l}\text { Great selectivity, affectability, strength, and reusability with a high electrocatalytic movement } \\
\text { toward paracetamol, sensitive electrochemical sensor, rescue human dental stem }\end{array}$ \\
\hline $\begin{array}{ll}\begin{array}{l}\text { Sodium- } \\
\text { substrate }\end{array} \quad \text { Titanium } \\
\end{array}$ & $\begin{array}{l}\text { Periodontal ligament stem cells expansion with GO, regenerative dentistry, Biocompatibility, } \\
\text { corrosion, strength, }\end{array}$ \\
\hline $\mathrm{G}-\mathrm{Ag}-\mathrm{TiO}_{2}$ & Antibacterial, antimicrobial \\
\hline
\end{tabular}

GO and rGO act as antimicrobial carriers providing development against many strains of microorganism and cause the least cytotoxic and oxidative damage. This can also be used as cancer treatment agents. It is found to be used with the biomaterial to enhance the bioactivity of the materials resulting in better output. Other agents who work as antibacterial and performing antimicrobial activity are GO-Ag nanoparticle (NPs), GO-Ag $\mathrm{PO}_{4} \mathrm{NPs}, \mathrm{G}-\mathrm{AgNPs}-$ PA, rGO-Ag NPs-PDDA (antibacterial), GO-AgNPs PDA NPs, G-AgNPs/PEI, rGO-PEIAgNPs- $\mathrm{Fe}_{2} \mathrm{O}_{3}$, rGO-Ag-CoFe $\mathrm{O}_{4}$, rGO-Ag-CoFe $2 \mathrm{O}_{5}$, GO-Ag NPS-PAA, GO-Ag- $\mathrm{TiO}_{2}$ (prevent infection and has antibacterial activity), minocycline hydrochloride-GO-Ti NPs (antibacterial) (Table 1). The main composition is GO (Graphene Oxide) which on addition with different nanoparticles form different product and give additional benefits, and the reduced graphene oxide ( $\mathrm{rGO}$ ) has several properties teeth implants, oral cancer treatment, good antimicrobial components, and imaging, restrain the development of E. coli, S. aureus, B. subtilis and also used in titanium dental implants, membranes for bone regeneration, resins, cement and adhesives, tooth whitening procedure and enhance bioactivity of biomaterials, tissue-engineering [133-147].

Some of the composites, along with antimicrobial activity, work as a treatment for cancer. Such composites provide additional benefits to overcome infections and diseases. Some of the examples are: rGO-PEI-AgNPs- $\mathrm{Fe}_{2} \mathrm{O}_{3}, \mathrm{rGO}-\mathrm{Ag}_{-} \mathrm{CoFe}_{2} \mathrm{O}_{4}, \mathrm{rGO}-\mathrm{Ag}-\mathrm{CoFe}_{2} \mathrm{O}_{5}$, etc. GO$\mathrm{N}=\mathrm{N}-\mathrm{GO} / \mathrm{PVA}$ helps in Increasing colon targeting capability and dwelling time inside the colon and hence improve colorectal cancer. GO-Ag nanoparticle can also use in toothpaste so it can prevent further from any infection in the teeth. Hydrogen peroxide cobalt-tetraphenyl porphyrin /rGO has an important role in dental treatment such as bleaching, mild antiseptic, relieve mouth irritation, gingivitis, dentures. $\mathrm{ZnO}$ is mainly used as temporary fixing contents 
and filling materials, for gingival dressings and together with filling materials as impression materials. Compounds viz. paracetamol (PCM) helps to cure toothaches in dentistry and fever. The ncCeO $2-\mathrm{RGO}$ with great selectivity, affectability, strength, and reusability, showed high electrocatalytic movement toward paracetamol [148-151].

Infection is the most common activity performed by the cosmopolitan microorganism, causing a biofilm formation over the decay. Graphene/zinc oxide nanocomposite (GZNC) has the potential for the biofilm caused by S. mutans. Acrylic teeth coated with graphene are used due to its cost-effectiveness, fracture-resistant, and low-density property are suitable for implantation [152]. Hydroxyapatite/GO NPs are used for treatment in different Orthopedic, medicine transfer, dental researcher \& treatment, has biological compatibility, defensive layers for dentistry against erosive procedures. Also, work as Fillers in dental or orthopedic applications, too, and during the process of metabolism, as some ROS (reactive oxygen species) are produced within the body, which could lead to the harmful output. Hydrazine hydrate act as a reducing agent, oxygen scavenger, source of drug hydralazine in Anti TB, as fuel. Polyethylene glycol, GO-Ag NPs-PDA with the application as wound dressing, antimicrobial, polymer, coating material, adsorbents coating in biomedical science, making dental material, fillings, biofilms formation. Also, Platinum $(\mathrm{Pt})$ loaded-graphene quantum dot composite, modified via polyethylene glycol, enhances the oral malignancy (oral squamous cell carcinoma) chemotherapeutic efficaciousness enhance the confinement in the Synthesis phase of the cell cycle, and lead to cell apoptosis, potentially raises the platinum inflation in both normoxia and hypoxia (state of oxygen normalcy) conditions inside cells, cancer remedial treatment therapy, treatment of cancer. Catalytic ozonation, dental restorations, and provide strengths and stiffness [153-154].

GO- $\mathrm{Fe}_{2} \mathrm{O}_{3}$ hybrid material can act as an efficient heterogeneous catalyst for the degradation of organic contaminants, which may provide insight into the design and development of high-efficiency visible-light photocatalyst for water treatment and $\mathrm{GO}-\mathrm{Fe}_{3} \mathrm{O}_{4}$ can be used as a photosensitizing agent in dental treatment like Applications of PDT(Photodynamic therapy in dentistry) in dentistry is growing rapidly: the treatment of oral cancer, bacterial and fungal infection therapies, and the photodynamic diagnosis (PDD) of the malignant transformation of oral lesions. Photodynamic antimicrobial chemotherapy (PACT) has been efficacious in the treatment of bacterial, fungal, parasitic, and viral infections. The absence of genotoxic and mutagenic effects of PDT is an important factor for long-term safety during treatment. PDT also represents a novel therapeutic approach in the management of oral biofilms. Thus, the oral cavity is especially suitable for PACT because it is relatively accessible to illumination [155-156]. Antibiotic effect of photocatalytic $\mathrm{TiO}_{2}$ (photocatalytic $\mathrm{TiO}_{2}$ has antibacterial effect on Lactobacillus acidophilus, Saccharomyces cerevisiae, and E. coli), GO$\mathrm{Bi}_{2} \mathrm{WO}_{6}$. Since $S$. mutans that cause dental caries can easily adhere to the tooth surface or orthodontic devices attached to tooth surfaces, the anti-adhesion effect of photocatalytic $\mathrm{TiO}_{2}$ was monitored [157]. The electrostatic interaction in nanoparticles makes it easy to uptake by cell walls and hence leads to its disintegration [158]. The large volume of these nanoparticles penetrates the cell membrane [159]. This mechanism beholds the basic criteria to use such nanoparticles to acts as an antibacterial and can be used in various medical fields [160].

\section{Comparison of Various Nanoparticles}

Various kinds of nanoparticles are being used with their distinct functions such as antimicrobial activity, cancer treatment, drug delivery, use of biomaterial for bone and tooth 
replacement [161]. A comparison can be analyzed of these nanoparticles in terms of their efficacy, application, cost, etc. Working efficacy and cost play a major role when these nanoparticles are used in medicine [162]. In accordance with here, cost, as well as applications of some nanoparticles which impart an important role in antimicrobial activity, are herewith compared and analyzed with those of others. As suggested, GO-AgNPs have wide applications for antibacterial activity and are cheap as compared with the other, i.e., GO- $\mathrm{Ag}_{3} \mathrm{PO}_{4} \mathrm{NPs}$ [163]. In accordance with it, rGO-AgNPs, as well as $\mathrm{rGO}-\mathrm{Cu}_{2} \mathrm{O}$, both have a similar activity that of antimicrobial, but when compared to both with their cost, rGO-AgNPs is much cheaper [164]. As proposed, G-AgNPs-PA, G-AgNPs/PEI, G-Ag- $\mathrm{TiO}_{2}$ are of similar function with antimicrobial activity, while G-AgNPs/PEI is cheapest among all of these three. The rGO-Ag NPs-PDDA, rGO-PEI-AgNPs-Fe $2 \mathrm{O}_{3}, \mathrm{rGO}-\mathrm{Ag}-\mathrm{CoFe}_{2} \mathrm{O}_{4}, \mathrm{rGO}-\mathrm{Ag}-\mathrm{CoFe}_{2} \mathrm{O}_{5}$ were compared for their efficacy as well as cost, as analyzed rGO-PEI-AgNPs- $\mathrm{Fe}_{2} \mathrm{O}_{3}$ was cheapest among all while rGO-Ag-CoFe $2 \mathrm{O}_{4}$, as well as rGO-Ag-CoFe2O5, were of similar price with almost equal efficacy [165]. As similar, some other nanoparticles were compared with each other where GOAg NPs-PDA was found to be cheapest as compared with these three nanoparticles $\mathrm{GO}-\mathrm{Fe}_{3} \mathrm{O}_{4}$, GO-Ag NPS-PAA and GO-Ag-Ti. As suggested, hydrazine hydrate, anti-toxin minocycline hydrochloride, minocycline hydrochloride-GO-Ti when compared with each other was observed that hydrazine hydrate was cheapest among these three as proposed hydrazine hydrate was found to be the cheapest of all nanoparticles mentioned above for antimicrobial activity. Some of the nanoparticles or nanomaterials have a great significance in dentistry, Orthopedic, wound dressing, etc. [166]. These include GO, and rGO, GO-Ag $\mathrm{PO}_{4} \mathrm{NPs}$, rGO-AgNPs, GOZnO, GO-Ag NPs-PDA, polyethylene glycol, Hydroxyapatite/GO NPs, Sodium- Titanium substrate. As a proposed comparison between GO and rGO, both of these have an exactly similar function in dentistry, but when compared in cost, the GO is much cheaper than that of rGO, and while compared with rGO-AgNPs, it is much more costly than GO and rGO. In accordance with it similarly, GO-Ag $\mathrm{PO}_{4} \mathrm{NPs}$, GO-ZnO, GO-Ag NPs-PDA were compared in terms of their wide application as well as cost. It was observed that all three are widely used in fracture or tooth implantation, but when compared to cost $\mathrm{GO}-\mathrm{ZnO}$ is the cheapest than all three mentioned here [167]. A wide application of nanoparticle is marked in cancer treatment via targeted drug delivery or by other means. Various nanoparticles used for cancer treatment are rGO-ZnO, rGO-Ag-CoFe2O5, G-AgNPs/PEI, Platinum (Pt) loaded-graphene quantum dot composite, modified via polyethylene glycol, GO-N=N-GO/PVA, Minocycline hydrochloride-GO-Ti, etc. [168-169]. As suggested when compared these all minocycline hydrochloride-GO-Ti is much of cost which may be far away from the use of middle-class person while Platinum (Pt) loaded-graphene quantum dot composite, modified via polyethylene glycol, has wide application, i.e., used as a chemotherapeutic agent for the treatment of colon cancer and is cheap, so it's among the reach common people.

\section{Conclusions}

In dentistry, there is a particular requirement to provide target delivery of drugs and medicinal approach, which is limited to localized effects only. On such criteria, graphene and its composites and different nanocomplex with other chemicals fulfill this need. Graphene forms nanocomposite quite easily compares to others and provide not one but more than one use at a time. Graphene is utilized mainly in complex nanocomposites and forms complex with a different polymer like PAA, PEI, polyethylene glycol that provides a target delivery approach. They provided particularly antibacterial property and used as dental fillings. The use 
of tobacco, cigarettes causes oral cancer in majorly young age adults. GO forms composites with silver, iron, cobalt. These nanocomposites provide target delivery of drugs and have less cytotoxicity along with bone regeneration property. Graphene oxide and rGo, along with nano compositions, are utilized in dentistry for fulfilling enormous purpose. It acts as an antimicrobial agent in various dental fillings and specifically to reduce the growth of bacteria. To increase inhibition of different strains of bacteria, GO-Ag nanoparticles are used. Some other examples are GO-ZnO nanoparticles, $\mathrm{rGO}-\mathrm{Cu}_{2} \mathrm{O}, \mathrm{GO}-\mathrm{Fe}_{3} \mathrm{O}_{3}$, rGO-Ag-PA, rGO-Ag-PEI, GO-Ag-Ti, GO-minocycline hydrochloride-Ti, etc. GO fulfills the basic need of dental implants and inhibits the growth of dental pathogens. Graphene up-regulates the bone formation by an increase in the expression of beta-catenin protein in cells, and they are used as anticancer. Some of the other derivatives of GO that gives cytotoxic activity is rGO-Ag$\mathrm{CoFe}_{2} \mathrm{O}_{4}$. Graphene forms complex derivatives with $\mathrm{Ti}$ and $\mathrm{Ag}$ and its complex give both antibacterial and decontamination properties. GO portrays hydrophobic property, which makes it to cause the least oxidative damage, has low cytotoxicity, and induce the least damage to the dental follicle. This leads to the use of graphene in fillings and dental implants. Graphene with titanium is used in dentistry as adhesives, fillings, tooth whitening procedures, and dental implants. Graphene oxide has appeared to bond well with hydroxyapatite, titanium, and potential biomaterials, and that resulted in the application of implants and fillings. Graphene$\mathrm{ZnO}$ nanocomposites can play the role of biofilm and hence protect the outermost layer of teeth enamel. This type of protection is comparably cost-effective and fracture-resistant and suitable for the implantation process. $\mathrm{GO}-\mathrm{Fe}_{3} \mathrm{O}_{4}, \mathrm{GO}-\mathrm{Fe}_{3} \mathrm{O}_{3}, \mathrm{GO}-\mathrm{MnFe}_{2} \mathrm{O}_{4}$ are utilized as antibacterial, photosensitive agents, heterogeneous catalysts for degradation of organic contaminants, lowcost adsorbents for removal of arsenic from water, etc. GO-CdS composite material is used as a gas sensor for $\mathrm{CO}_{2}$ based on its electrocatalytic behavior. For toothache recovery, paracetamol is used, and GO-PCM complex can be used to deliver at a particular target. We can conclude that the graphene families and its oxides, functionalized metals oxides, and complex formulations at different concentrations give the vast application in dentistry and costeffective too. It has a good antimicrobial property and is used in oral cancer, teeth infection, and gum related diseases.

\section{Funding}

This research received no external funding.

\section{Acknowledgments}

The authors would like to acknowledge the facilities provided by M.M. (Deemed to be University) Mullana (Ambala) for carrying out this work, and also thankful to the Institute of Nuclear Medicine and Allied Science (DRDO), New Delhi, for providing the new ideas.

\section{Conflicts of Interest}

The authors declare no conflict of interest.

\section{References}

1. Gao, L.; Xu, T.; Huang, G.; Jiang, S.; Gu, Y.; Chen, F. Oral microbiomes: More and more importance in oral cavity and whole body. Prot. Cell. 2018, 9(5), 488-500. https://doi.org/10.1007/s13238-018-0548-1.

2. He, J.; Zhu, X.; Qi, Z.; Wang, C.; Mao, X.; Zhu, C.; Tang, Z. Killing dental pathogens using antibacterial graphene oxide. ACS Appl. Mater. Interf. 2015, 7, 5605-5611. https://doi.org/10.1021/acsami.5b01069. 
3. Wade, W.G. The oral microbiome in health and disease. Pharmacol. Res. 2013, 69, 137-143. https://doi.org/10.1016/j.phrs.2012.11.006.

4. Ghannoum, M.A.; Jurevic, R.J.; Mukherjee, P.K.; Cui, F.; Sikaroodi, M.; Naqvi, A. Characterization of the oral fungal microbiome (mycobiome) in healthy individuals. PLOS Path. 2010, 6. https://doi.org/10.1371/journal.ppat.1000713.

5. Dupuy, A.K.; David, M.S.; Lu, L.; Heider, T.N.; Peterson, J.D.; Montano, E.A. Redefining the human oral mycobiome with improved practices in amplicon-based taxonomy: Discovery of Malassezia as a prominent commensal. PLOS One 2014, 1. https://doi.org/10.1371/journal.pone.0090899.

6. Mukherjee, P.K.; Chandra, J.; Retuerto, M.; Sikaroodi, M.; Brown, R.E.; Jurevic, R. Oral mycobiome analysis of HIV-infected patients: Identification of Pichia as an antagonist of opportunistic fungi. PLoS Path. 2014, 10. https://doi.org/10.1371/journal.ppat.1003996.

7. Krom, B.P.; Kidwai, S.; Ten Cate, J.M. Candida and other fungal species. J. Dental Res. 2014, 93, 445451. https://doi.org/10.1177/0022034514521814.

8. Palmer Jr, R.J. Composition and development of oral bacterial communities. Periodontol. 2013, 64, 2039. https://doi.org/10.1111/j.1600-0757.2012.00453.x.

9. Zhou, Y.; Gao, H.; Mihindukulasuriya, K.A.; La Rosa, P.S.; Wylie, K.M.; Vishnivetskaya, T.; Weinstock, G.M. Biogeography of the ecosystems of the healthy human body. Genome Biol. 2013, 14, R1. https://doi.org/10.1186/gb-2013-14-1-r1.

10. Zaura, E.; Nicu, E.A.; Krom, B.P.; Keijser, B.J.F. Acquiring and maintaining a normal oral microbiome: Current perspective. Front. Cell. Infect. Microbiol. 2014, 4. https://doi.org/10.3389/fcimb.2014.00085.

11. Kilian, M.; Chapple, I.L.C.; Hannig, M.; Marsh, P.D.; Meuric, V.; Pedersen, A.M.L.; Zaura, E. The oral microbiome: An update for oral healthcare professionals. British Dental J. 2016, 221, 657666. https://doi.org/10.1038/sj.bdj.2016.865.

12. Fakhruddin, K.S.; Ngo, H.C.; Samaranayake, L.P. Cariogenic microbiome and microbiota of the early primary dentition: A contemporary overview. Oral Dis. 2018. https://doi.org/10.1111/odi.12932.

13. Hasan, S.; Singh, K.; Danisuddin, M.; Verma, P. K.; Khan, A.U. Inhibition of major virulence pathways of Streptococcus mutans by quercitrin and deoxy nojirimycin: A synergistic approach of infection control. PLoS One. 2014, 9, e91736. https://doi.org/10.1371/journal.pone.0091736.

14. Abranches, J.; Miller, J.H.; Martinez, A.R.; Simpson-Haidaris, P. J.; Burne, R.A.; Lemos, J.A. The collagen-binding protein CNM is required for Streptococcus mutans adherence to and intracellular invasion of human coronary artery endothelial cells. Infect. Immun. 2011, 79, 22772284. https://doi.org/10.1128/iai.00767-10.

15. Dmitriev, A.; Mohapatra, S.S.; Chong, P.; Neely, M.; Biswas, S.; Biswas, I. CovR-controlled global regulation of gene expression in Streptococcus mutans. PLoS One, 2011, 6, e20127. https://doi.org/10.1371/journal.pone.0020127.

16. Koo, H. Inhibition of Streptococcus mutans biofilm accumulation and polysaccharide production by apigenin and tt-farnesol. J. Antimicrob. Chemoth. 2003, 52, 782-789. https://doi.org/10.1093/jac/dkg44.

17. Krol, J.E.; Biswas, S.; King, C.; Biswas, I. SMU746-SMU747, a putative membrane permease complex, is involved in aciduricity, acidogenesis, and biofilm formation in Streptococcus mutans. J. Bacteriol. 2013, 196, 129-139. https://doi.org/10.1128/jb.00960-13.

18. Singh, M.; Renu; Kumar V.; Upadhyay, S.K.; Singh R.; Yadav, M.; Seema; Kumari, S.; Sharma, A.K.; Manikandan, S. Biomimetic synthesis of silver nanoparticle from aqueous extract of Saraca indica and its profound antibacterial activity. Biointerface Res. Appl. Chem. 2021, 11, 8110-8120. https://doi.org/10.33263/BRIAC111.81108120.

19. Ximenez-Fyvie, L.A.; Haffajee, A.D.; Socransky, S.S. Comparison of the microbiota of supra- and subgingival plaque in health and periodontitis. J. Clin. Periodontol. 2000, 27, 648-657. https://doi.org/10.1034/j.1600-051x.2000.027009648.x.

20. Paster, B.J.; Boches, S.K.; Galvin, J.L.; Ericson, R.E.; Lau, C.N.; Levanos, V.A; Dewhirst, F.E. Bacterial diversity in human subgingival plaque. J. Bacteriol. 2001, 183, 3770-3783. https://doi.org/10.1128/jb.183.12.3770-3783.2001.

21. Gomes, B.P.F.A.; Pinheiro, E.T.; Gade-Neto, C.R.; Sousa, E.L.R.; Ferraz, C.C.R.; Zaia, A.A.; Souza-Filho, F.J. Microbiological examination of infected dental root canals. Oral Microbiol. Immunol. 2004, 19, 7176. https://doi.org/10.1046/j.0902-0055.2003.00116.x.

22. Ajayan, P.M.; Zhou, O.Z. Applications of carbon nanotubes. Carbon Nanotubes, 2001, 391-425. https://doi.org/10.1007/3-540-39947-x_14.

23. McIntyre, R.A. Common nano-materials and their use in real world applications. Sci. Prog. 2012, 95, 122. https://doi.org/10.3184/003685012x13294715456431.

24. Pacholski, C.; Yu, C.; Miskelly, G.M.; Godin, D.; Sailor, M.J. Reflective interferometric fourier transform spectroscopy: A self-compensating label-free immunosensor using double-layers of porous $\mathrm{SiO}_{2}$. J. Amer. Chem. Soc. 2006, 128, 4250-4252. https://doi.org/10.1021/ja056702b.

25. Paulose, M.; Shankar, K.; Yoriya, S.; Prakasam, H.E.; Varghese, O.K.; Mor, G.K.; Grimes, C.A. Anodic growth of highly ordered $\mathrm{TiO}_{2}$ nanotube arrays to $134 \mu \mathrm{m}$ in length. J. Phys. Chem. B. 2006, 110, 1617916184. https://doi.org/10.1021/jp064020k. 
26. Kane, C.L. Erasing electron mass. Nature. 2005, 438, 168-170. https://doi.org/10.1038/438168a.

27. Bonaccorso, F.; Sun, Z.; Hasan, T.; Ferrari, A.C. Graphene photonics and optoelectronics. Nature Photon. 2010, 4, 611-622. https://doi.org/10.1038/nphoton.2010.186.

28. Xu, M.; Fujita, D.; Hanagata, N. Perspectives and challenges of emerging single-molecule DNA sequencing technologies. Small 2009, 5, 2638-2649. https://doi.org/10.1002/smll.200900976.

29. Stoller, M.D.; Park, S.; Zhu, Y.; An, J.; Ruoff, R.S. Graphene-based ultracapacitors. Nano Lett. 2008, 8, 3498-3502. https://doi.org/10.1021/nl802558y.

30. Hu, W.; Peng, C.; Luo, W.; Lv, M.; Li, X.; Li, D.; Fan, C. Graphene-based antibacterial paper. ACS Nano 2010, 4, 4317-4323. https://doi.org/10.1021/nn101097v.

31. Mejías-Carpio, I.E.; Santos, C.M.; Wei, X.; Rodrigues, D.F. Toxicity of a polymer-graphene oxide composite against bacterial planktonic cells, biofilms, and mammalian cells. Nanosc. 2012, 4, 4746. https://doi.org/10.1039/c2nr30774j.

32. Priyadarsini, S.; Mukherjee, S.; Mishra, M. Nanoparticles used in dentistry: A review. J. Oral Biol. Craniofac. Res. 2018, 8, 58-67. https://doi.org/10.1016/j.jobcr.2017.12.004.

33. Kulshrestha, S.; Khan, S.; Meena, R.; Singh, B.R.; Khan, A.U. A graphene/zinc oxide nanocomposite film protects dental implant surfaces against cariogenic Streptococcus mutans. Biofoul. 2014, 30, 1281-1294. https://doi.org/10.1080/08927014.2014.983093.

34. Bartolo, P.; Kruth, J.P.; Silva, J.; Levy, G.; Malshe, A.; Rajurkar, K.; Leu, M. Biomedical production of implants by additive electrochemical and physical processes. CIRP Ann. 2012, 61, 635-655. https://doi.org/10.1016/j.cirp.2012.05.005.

35. Wu, M.C.; Deokar, A.R.; Liao, J.H.; Shih, P.Y.; Ling, Y.C. Graphene-based photothermal agent for rapid and effective killing of bacteria. ACS Nano. 2013, 7, 1281-1290. https://doi.org/10.1021/nn304782d.

36. Dai, K.; Lu, L.; Liang, C.; Dai, J.; Zhu, G.; Liu, Z.; Zhang, Y. Graphene oxide modified ZnO nanorods hybrid with high reusable photocatalytic activity under UV-LED irradiation. Mater. Chem. Phys. 2014, 143, 1410-1416. https://doi.org/10.1016/j.matchemphys.2013.11.055.

37. Ocsoy, I.; Paret, M.L.; Ocsoy, M.A.; Kunwar, S.; Chen, T.; You, M.; Tan, W. Nanotechnology in plant disease management: DNA-directed silver nanoparticles on graphene oxide as an antibacterial against Xanthomonas perforans. ACS Nano. 2013, 7, 8972-8980. https://doi.org/10.1021/nn4034794.

38. Wang, Y.; Li, Z.; Wang, J.; Li, J.; Lin, Y. Graphene and graphene oxide: Biofunctionalization and applications in biotechnology. Trends Biotechnol. 2011, 29, 205-212. https://doi.org/10.1016/j.tibtech.2011.01.008.

39. Ma, J.; Zhang, J.; Xiong, Z.; Yong, Y.; Zhao, X.S. Preparation, characterization and antibacterial properties of silver-modified graphene oxide. J. Mater. Chem 2011, 21, 3350-3352. https://doi.org/10.1039/c0jm02806a.

40. Xu, W.P.; Zhang, L.C.; Li, J.P.; Lu, Y.; Li, H.H.; Ma, Y.N.; Yu, S.H. Facile synthesis of silver/graphene oxide nanocomposites and their enhanced antibacterial properties. J. Mater. Chem. 2011, 21, 4593. https://doi.org/10.1039/c0jm03376f.

41. Tang, J.; Chen, Q.; Xu, L.; Zhang, S.; Feng, L.; Cheng, L.; Peng, R. Graphene oxide-silver nanocomposite as a highly effective antibacterial agent with species-specific mechanisms. ACS Appl. Mater. Interf. 2013, 5, 3867-3874. https://doi.org/10.1021/am4005495.

42. De Faria, A.F.; Martinez, D.S.T.; Meira, S.M.M.; de Moraes, A.C.M.; Brandelli, A.; Filho, A.G.S.; Alves, O.L. Anti-adhesion and antibacterial activity of silver nanoparticles supported on graphene oxide sheets. Coll. Surf. B: Biointerface 2014, 113, 115-124. https://doi.org/10.1016/j.colsurfb.2013.08.006.

43. Chang, Y.; Yang, S.T.; Liu, J.H.; Dong, E; Wang, Y.; Cao, A.; Wang, H. In vitro toxicity evaluation of graphene oxide on A549 cells. Toxicol. Lett. 2011, 200, 201-210. https://doi.org/10.1016/j.toxlet.2010.11.016.

44. Kachoei, M.Y.; Divband, B.; Tabriz, F.D.; Helali, Z.N.; Esmailzadeh, M.A comparative study of antibacterial effects of mouthwashes containing $\mathrm{Ag} / \mathrm{ZnO}$ or $\mathrm{ZnO}$ nanoparticles with chlorhexidine and investigation of their cytotoxicity. Nanomed. J. 2018, $\quad 5, \quad 102-110$. https://doi.org/10.22038/NMJ.2018.005.007.

45. Hu, W.; Peng, C.; Luo, W.; Lv, M.; Li, X.; Li, D.; Fan, C. Graphene-based antibacterial paper. ACS Nano. 2010, 4, 4317-4323. https://doi.org/10.1021/nn101097v.

46. Hui, L.; Piao, J.G.; Auletta, J.; Hu, K.; Zhu, Y.; Meyer, T.; Yang, L. Availability of the basal planes of graphene oxide determines whether it is antibacterial. ACS Appl. Mater. Interf. 2014, 6, 13183-13190. https://doi.org/10.1021/am503070z.

47. Krishna, K.V.; Ménard-Moyon, C.; Verma, S.; Bianco, A. Graphene-based nanomaterials for nanobiotechnology and biomedical applications. Nanomed. 2013, 8, 16691688. https://doi.org/10.2217/nnm.13.140.

48. Zhao, J.; Deng, B.; Lv, M.; Li, J.; Zhang, Y.; Jiang, H.; Fan, C. Graphene oxide-based antibacterial cotton fabrics. Adv. Health. Mater. 2013, 2, 1259-1266. https://doi.org/10.1002/adhm.201200437.

49. Priyadarsini, S.; Mohanty, S.; Mukherjee, S.; Basu, S.; Mishra, M. Graphene and graphene oxide as nanomaterials for medicine and biology application. J. Nanostruct. Chem. 2018, 8, 123137. https://doi.org/10.1007/s40097-018-0265-6. 
50. Olivi, M.; Zanni, E.; De Bellis, G.;Talora, C.; Sarto, M. S.; Palleschi, C.; Fiorito, S. Inhibition of microbial growth by carbon nanotube networks. Nanos. 2013, 5, 9023. https://doi.org/10.1039/c3nr02091f.

51. Akhavan, O.; Ghaderi, E. Photocatalytic reduction of graphene oxide nanosheets on $\mathrm{TiO}_{2}$ thin film for photoinactivation of bacteria in solar light irradiation. J. Phys. Chem. C 2009, 113, 2021420220. https://doi.org/10.1021/jp906325q.

52. Liu, J.; Liu, L.; Bai, H.; Wang, Y.; Sun, D.D. Gram-scale production of graphene oxide-TiO ${ }_{2}$ nanorod composites: Towards high-activity photocatalytic materials. Appl. Catal. B: Environ. 2011. https://doi.org/10.1016/j.apcatb.2011.05.007.

53. Zhu, Y.; Murali, S.; Cai, W.; Li, X.; Suk, J.W.; Potts, J. R.; Ruoff, R.S. Graphene and graphene oxide: Synthesis, properties, and applications. Adv. Mater. 2010, 22, 3906-3924. https://doi.org/10.1002/adma.201001068.

54. Stankovich, S.; Dikin, D.A.; Dommett, G.H.B.; Kohlhaas, K.M.; Zimney, E.J.; Stach, E.A.; Ruoff, R.S. Graphene-based composite materials. Nature. 2810, 286. https://doi.org/10.1038/nature04969.

55. Geim, A.K. Graphene: Status and prospects. Sci. 2009, 324, 1530-1534. https://doi.org/10.1126/science.1158877.

56. De Bellis, G.; Tamburrano, A.; Dinescu, A.; Santarelli, M.L.; Sarto, M.S. Electromagnetic properties of composites containing graphite nanoplatelets at radio frequency. Carbon. 2011, 49, 4291-4300. https://doi.org/10.1016/j.carbon.2011.06.008.

57. Zhu, Y.; Murali, S.; Cai, W.; Li, X.; Suk, J.W.; Potts, J.R.; Ruoff, R.S. Graphene and graphene oxide: Synthesis, properties, and applications. Adv. Mater. 2010, 22, 3906-3924. https://doi.org/10.1002/adma.201001068.

58. Huang, X.; Yin, Z.; Wu, S.; Qi, X.; He, Q.; Zhang, Q.; Zhang, H. Graphene-based materials: Synthesis, characterization, properties, and applications. Small. 2011, 7, 1876-1902. https://doi.org/10.1002/smll.201002009.

59. Jiang, H. Chemical preparation of graphene-based nanomaterials and their applications in chemical and biological sensors. Small. 2011. https://doi.org/10.1002/smll.201002352.

60. Guo, S.; Dong, S. Graphene nano sheet: synthesis, molecular engineering, thin film, hybrids, and energy and analytical applications. Chem. Soc. Rev. 2011, 40, 2644. https://doi.org/10.1039/c0cs00079e.

61. Sun, X.; Liu, Z.; Welsher, K.; Robinson, J.T.; Goodwin, A.; Zaric, S.; Dai, H. Nano-graphene oxide for cellular imaging and drug delivery. Nano Res. 2008, 1, 203-212. https://doi.org/10.1007/s12274-0088021-8.

62. Hu, W.; Peng, C.; Luo, W.; Lv, M.; Li, X.; Li, D.; Fan, C. Graphene-based antibacterial paper. ACS Nano. 2010, 4, 4317-4323. https://doi.org/10.1021/nn101097v.

63. Yang, K.; Zhang, S.; Zhang, G.; Sun, X.; Lee, S.T.; Liu, Z. Graphene in mice: Ultrahigh in vivo tumor uptake and efficient photothermal therapy. Nano Lett. 2010, 10, 3318-3323. https://doi.org/10.1021/nl100996u.

64. Zanni, E.; De Bellis, G.; Bracciale, M.P.; Broggi, A.; Santarelli, M.L.; Sarto, M.S.; Uccelletti, D. Graphite nanoplatelets and Caenorhabditis elegans: Insights from an in vivo model. Nano Lett. 2012, 12, 27402744. https://doi.org/10.1021/nl204388p.

65. Rago, I.; Bregnocchi, A.; Zanni, E.; D’Aloia, A.G.; De Angelis, F.; Bossu, M.; Sarto, M.S. Antimicrobial activity of graphene nanoplatelets against Streptococcus mutans. IEEE $15^{\text {th }}$ Int. Conf. Nanotechnol. 2015. https://doi.org/10.1109/nano.2015.7388945.

66. Zanni, E.; Chandraiahgari, C.; De Bellis, G.; Montereali, M.; Armiento, G.; Ballirano, P.; Uccelletti, D. Zinc oxide nanorods-decorated graphene nanoplatelets: A promising antimicrobial agent against the cariogenic bacterium Streptococcus mutans. Nanomater. 2016, 6, 179. https://doi.org/10.3390/nano6100179.

67. Yin, P.T.; Shah, S.; Chhowalla, M.; Lee, K.B. Design, synthesis, and characterization of graphenenanoparticle hybrid materials for bioapplications. Chem. Rev. 2015, 115, 2483-2531. https://doi.org/10.1021/cr500537t.

68. Li, Q.; Mahmood, N.; Zhu, J.; Hou, Y.; Sun, S. Graphene and its composites with nanoparticles for electrochemical energy applications. Nano Today. 2014, 9, 668-683. https://doi.org/10.1016/j.nantod.2014.09.002.

69. Dehbalaei, M.G.; Foroughifar, N.; Pasdar, H. Facile green one-pot synthesis of pyrano [2, 3-c] pyrazole and 1,8-dioxo-decahydroacridine derivatives using graphene oxide as a carbocatalyst and their biological evaluation as potent antibacterial agents. Biointerface Res. Appl. Chem. 2018, 8, 3016-3022.

70. Sarosi, C.; Biris, A.R.; Antoniac, A.; Boboia, S.; Alb, C.; Antoniac, I.; Moldovan, M. The nanofiller effect on properties of experimental graphene dental nanocomposites. J. Adhes. Sci.Technol. 2016, 30, 17791794. https://doi.org/10.1080/01694243.2016.1161969.

71. Ibrahim, M.A.; Elhaes, H.; El-Khodary, S.A.; Morsy, M.; Refaat, A.; Yahia, I.S.; Zahran, H.Y. Molecular modeling analyses for the effect of alkali metal oxides on graphene. Biointerface Res. Appl. Chem. 2018, $8,3522-3525$. 
72. He, J.; Zhu, X.; Qi, Z.; Wang, C.; Mao, X.; Zhu, C.; Tang, Z. Killing dental pathogens using antibacterial graphene oxide. ACS Appl. Mater. Interf. 2015, 7, 5605-5611. https://doi.org/10.1021/acsami.5b01069.

73. Kumar, P.; Huo, P.; Zhang, R.; Liu, B. Antibacterial properties of graphene-based nanomaterials. Nanomater. 2019, 9(5), 737. https://doi.org/10.3390/nano9050737.

74. Gurunathan, S.; Woong Han, J.; Abdal Daye, A.; Eppakayala, V.; Kim, J. Oxidative stress-mediated antibacterial activity of graphene oxide and reduced graphene oxide in Pseudomonas aeruginosa. Int. J. Nanomed. 2012, 5901. https://doi.org/10.2147/ijn.s37397.

75. Gurunathan, S.; Han, J. W.; Dayem, A. A.; Eppakayala, V.; Park, M.R.; Kwon, D.N.; Kim, J.H. Antibacterial activity of dithiothreitol reduced graphene oxide. J. Indust. Engin. Chem. 2013, 19, 12801288. https://doi.org/10.1016/j.jiec.2012.12.029.

76. Sengupta, I.; Bhattacharya, P.; Talukdar, M.; Neogi, S.; Pal, S.K.; Chakraborty, S. Bactericidal effect of graphene oxide and reduced graphene oxide: Influence of shape of bacteria. Collo. Interf. Sci. Comm. 2019, 28, 60-68. https://doi.org/10.1016/j.colcom.2018.12.001.

77. Nguyen, V. H.; Kim, B.K.; Jo, Y.L.; Shim, J.J. Preparation and antibacterial activity of silver nanoparticlesdecorated graphene composites. J. Supercrit. Fluids. 2012, 72, 28-35. https://doi.org/10.1016/j.supflu.2012.08.005.

78. Deng, C.H.; Gong, J.L.; Ma, L.L.; Zeng, G.M.; Song, B.; Zhang, P.; Huan, S.Y. Synthesis, characterization and antibacterial performance of visible light-responsive $\mathrm{Ag}_{3} \mathrm{PO}_{4}$ particles deposited on graphene nanosheets. Proc. Safety Environ. Prot. 2017, 106, 246-255. https://doi.org/10.1016/j.psep.2017.01.009.

79. Moghayedi, M.; Goharshadi, E. K.; Ghazvini, K.; Ahmadzadeh, H.; Ranjbaran, L.; Masoudi, R.; Ludwig, R. Kinetics and mechanism of antibacterial activity and cytotoxicity of Ag-RGO nanocomposite. Collo. Surf. B: Biointerface 2017, 159, 366-374. https://doi.org/10.1016/j.colsurfb.2017.08.001.

80. Kavitha, T.; Gopalan, A. I.; Lee, K.P.; Park, S.Y. Glucose sensing, photocatalytic and antibacterial properties of graphene-ZnO nanoparticle hybrids. Carbon. 2012, 50, 2994-3000. https://doi.org/10.1016/j.carbon.2012.02.082.

81. Trinh, L.T.; Quynh, L.A.B.; Hieu, N.H. Synthesis of zinc oxide/graphene oxide nanocomposite material for antibacterial application. Int. J. Nanotechnol. 2018, 15, 108. https://doi.org/10.1504/ijnt.2018.089542.

82. Gao, P.; Liu, J.; Sun, D.D.; Ng, W. Graphene oxide-CdS composite with high photocatalytic degradation and disinfection activities under visible light irradiation. J. Hazard. Mater. 2013, 251, 412-420. https://doi.org/10.1016/j.jhazmat.2013.02.003.

83. Yang, Z.; Hao, X.; Chen, S.; Ma, Z.; Wang, W.; Wang, C.; Guo, Z. Long-term antibacterial stable reduced graphene oxide nanocomposites loaded with cuprous oxide nanoparticles. J. Collo. Interf. Sci. 2018. https://doi.org/10.1016/j.jcis.2018.08.053.

84. Deng, C.H.; Gong, J.L.; Zeng, G.M.; Niu, C.G.; Niu, Q.Y.; Zhang, W.; Liu, H.Y. Inactivation performance and mechanism of Escherichia coli in aqueous system exposed to iron oxide loaded graphene nanocomposites. J. Hazard. Mater. 2014, 276, 66-76. https://doi.org/10.1016/j.jhazmat.2014.05.011.

85. Santhosh, C.; Kollu, P.; Doshi, S.; Sharma, M.; Bahadur, D.; Vanchinathan, M.T.; Grace, A.N. Adsorption, photodegradation and antibacterial study of graphene-Fe3O4 nanocomposite for multipurpose water purification application. $R S C A d v$. 2014, 4, 28300-28308. https://doi.org/10.1039/c4ra02913e.

86. Chella, S.; Kollu, P.; Komarala, E.V.P.R.; Doshi, S.; Saranya, M.; Felix, S.; Grace, A.N. Solvothermal synthesis of $\mathrm{MnFe}_{2} \mathrm{O}_{4}$-graphene composite-Investigation of its adsorption and antimicrobial properties. Appl. Surf. Sci. 2015, 327, 27-36. https://doi.org/10.1016/j.apsusc.2014.11.096.

87. Chen, C.; Cao, S.; Yu, W.; Xie, X.; Liu, Q.; Tsang, Y.; Xiao, Y. Adsorption, photocatalytic and sunlightdriven antibacterial activity of $\mathrm{Bi}_{2} \mathrm{WO}_{6} /$ graphene oxide nanoflakes. Vacuum. 2015, 116, 48-53. https://doi.org/10.1016/j.vacuum.2015.02.031.

88. Shen, J.; Shi, M.; Yan, B.; Ma, H.; Li, N.; Ye, M. One-pot hydrothermal synthesis of Ag-reduced graphene oxide composite with ionic liquid. J.Mater. Chem. 2011, 21, 7795. https://doi.org/10.1039/c1jm10671f.

89. Wang, N.; Hu, B.; Chen, M.L.; Wang, J.H. Polyethylenimine mediated silver nanoparticle-decorated magnetic graphene as a promising photothermal antibacterial agent. Nanotechnol. 2015, 26, 195703. https://doi.org/10.1088/0957-4484/26/19/195703.

90. Ma, S.; Zhan, S.; Jia, Y.; Zhou, Q. Highly efficient antibacterial and $\mathrm{Pb}(\mathrm{II})$ removal effects of $\mathrm{Ag}-\mathrm{CoFe}_{2} \mathrm{O}_{4}-$ GO Nanocomposite. ACS Appl. Mater. Interf. 2015, 7, 10576-10586. https://doi.org/10.1021/acsami.5b02209.

91. Rizzello, L.;Pompa, P. P. Nanosilver-based antibacterial drugs and devices: Mechanisms, methodological drawbacks, and guidelines. Chem. Soc. Rev. 2014, 43, 1501-1518. https://doi.org/10.1039/c3cs60218d.

92. Tai, Z.; Ma, H.; Liu, B.; Yan, X.;Xue, Q. Facile synthesis of Ag/GNS-g-PAA nanohybrids for antimicrobial applications. Collo. Surf. B: Biointerface 2012, 89, 147-151. https://doi.org/10.1016/j.colsurfb.2011.09.006.

93. Zhou, H.; Liu, Y.; Chi, W.; Yu, C.; Yu, Y. Preparation and antibacterial properties of Agpolydopamine/graphene oxide sheet nanocomposite. Appl. Surf. Sci. 2013, 282, 181-185. https://doi.org/10.1016/j.apsusc.2013.05.099. 
94. Saito, T.; Ogawa, M.; Hata, Y.; Bessho, K. Acceleration effect of human recombinant bone morphogenetic protein-2 on differentiation of human pulp cells into odontoblasts. J. Endodont. 2004, 30, $205-208$. https://doi.org/10.1097/00004770-200404000-00005.

95. Qin, W.; Yang, F.; Deng, R.; Li, D.; Song, Z.; Tian, Y.; Lin, Z. Smad 1/5 Is involved in bone morphogenetic protein-2-induced odontoblastic differentiation in human dental pulp cells. J. Endodont. 2012, 38, 66-71. https://doi.org/10.1016/j.joen.2011.09.025.

96. Li, J.; Huang, X.; Xu, X.; Mayo, J.; Bringas, P.; Jiang, R.; Chai, Y. SMAD4-mediated WNT signaling controls the fate of cranial neural crest cells during tooth morphogenesis. Develop. 2011, 138, 1977-1989. https://doi.org/10.1242/dev.06134.

97. Yang, J.; Ye, L.; Hui, T.Q.; Yang, D.M.; Huang, D.M.; Zhou, X.D.; Wang, C.L. Bone morphogenetic protein 2-induced human dental pulp cell differentiation involves p38 mitogen-activated protein kinaseactivated canonical WNT pathway. Int. J. Oral Sci. 2015, 7, 95-102. https://doi.org/10.1038/ijos.2015.7.

98. Nakashima, M. Bone morphogenetic proteins in dentin regeneration for potential use in endodontic therapy. Cytokine Growth Fact. Rev. 2005, 16, 369-376. https://doi.org/10.1016/j.cytogfr.2005.02.011.

99. Chen, D.; Zhao, M.; Mundy, G.R. Bone Morphogenetic Proteins. Growth Fact. 2004, 22, 233-241, https://doi.org/10.1080/08977190412331279890.

100. Nakashima, M.; Reddi, A.H. The application of bone morphogenetic proteins to dental tissue engineering. Nature Biotechnol. 2003, 21, 1025-1032. https://doi.org/10.1038/nbt864.

101. Gautschi, O.P.; Frey, S.P.; Zellweger, R. Bone morphogenetic proteins in clinical applications. ANZ J. Surg. 2007, 77, 626-631. https://doi.org/10.1111/j.1445-2197.2007.04175.x.

102. La, W.G.; Park, S.; Yoon, H.H.; Jeong, G.J.; Lee, T.J.; Bhang, S.H.; Kim, B.S. Delivery of a therapeutic protein for bone regeneration from a substrate coated with graphene oxide. Small. 2013, 9, 4051-4060. https://doi.org/10.1002/smll.201300571.

103. Dubey, N.; Rajan, S.S.; Bello, Y.D.; Min, K.S.; Rosa, V. Graphene nanosheets to improve physicomechanical properties of bioactive calcium silicate cements. Mater. 2017, 10, 606. https://doi.org/10.3390/ma10060606.

104. Kim, B.S.; La, W.G.;Jin, M.; Park, S.; Yoon, H.H.; Jeong, G.J.; Char, K. Delivery of bone morphogenetic protein-2 and substance-P using graphene oxide for bone regeneration. Int. J. Nanomed. 2014, 107. https://doi.org/10.2147/ijn.s50742.

105. Jin, J.; Zhang, L.; Shi, M.; Zhang, Y.; Wang, Q. Ti-GO-Ag nanocomposite: The effect of content level on the antimicrobial activity and cytotoxicity. Int. J. Nanomed. 2017, 12, 4209-4224. https://doi.org/10.2147/ijn.s134843.

106. Qian, W.; Qiu, J.; Su, J.; Liu, X. Minocycline hydrochloride loaded on titanium by graphene oxide: an excellent antibacterial platform with the synergistic effect of contact-killing and release-killing. Biomater. Sci. 2018, 6, 304-313.https://doi.org/10.1039/c7bm00931c.

107. Rosa, V.; Xie, H.; Dubey, N.; Madanagopal, T. T.; Rajan, S. S.; Morin, J. L. P.; Castro Neto, A. H. Graphene oxide-based substrate: physical and surface characterization, cytocompatibility and differentiation potential of dental pulp stem cells. Dental Mater. 2016, 32, 1019-1025. https://doi.org/10.1016/j.dental.2016.05.008.

108. Olteanu, D.; Filip, A.; Socaci, C. Biris, A. R.; Filip, X.; Coros, M.; Pruneanu, S. Cytotoxicity assessment of graphene-based nanomaterials on human dental follicle stem cells. Collo. Surf. B: Biointerface 2015, 136, 791-798. https://doi.org/10.1016/j.colsurfb.2015.10.023.

109. Peng, J.; Lin, J.; Chen, Z.; Wei, M.; Fu, Y.; Lu, S.; Zhao, W. Enhanced antimicrobial activities of silvernanoparticle-decorated reduced graphene nanocomposites against oral pathogens. Mater. Sci. Engin. C 2017, 71, 10-16. https://doi.org/10.1016/j.msec.2016.09.070.

110. Ramadas, M.; Bharath, G.; Ponpandian, N.; Ballamurugan, A.M. Investigation on biophysical properties of hydroxyapatite/graphene oxide (HAp/GO) based binary nanocomposite for biomedical applications. Mater. Chem. Phys. 2017, 199, 179-184. https://doi.org/10.1016/j.matchemphys.2017.07.001.

111. Pachauri, N.; Dave, K.; Dinda, A.; Solanki, P.R. Cubic $\mathrm{CeO}_{2}$ implanted reduced graphene oxide-based highly sensitive biosensor for non-invasive oral cancer biomarker detection. J. Mater. Chem. B 2018, 6, 3000-3012. https://doi.org/10.1039/c8tb00653a.

112. Fiorillo, M.; Verre, A. F.; Iliut, M.; Peiris-Pagés, M.; Ozsvari, B.; Gandara, R.; Lisanti, M. P. Graphene oxide selectively targets cancer stem cells, across multiple tumor types: Implications for non-toxic cancer treatment, via differentiation-based nano-therapy. Oncotarget. 2015, 6, 3553-3562. https://doi.org/10.18632/oncotarget.3348.

113. Kumar, S.; Sharma, J.G.; Maji, S.; Malhotra, B.D. Nanostructured zirconia decorated reduced graphene oxide based efficient biosensing platform for non-invasive oral cancer detection. Biosens. Bioelectron. 2016, 78, 497-504. https://doi.org/10.1016/j.bios.2015.11.084.

114. Lee, J.H.; Sahu, A.; Jang, C.; Tae, G. The effect of ligand density on in vivo tumor targeting of nanographene oxide. J. Control. Rel.. 2015, 209, 219-228. https://doi.org/10.1016/j.jconrel.2015.04.035.

115. Wei, Z.; Yin, X.; Cai, Y.; Xu, W.; Song, C.; Wang, Y.; Han, W. Antitumor effect of a Pt-loaded nanocomposite based on graphene quantum dots combats hypoxia-induced chemoresistance of oral squamous cell carcinoma. Int. J. Nanomed. 2018, 13, 1505-1524. https://doi.org/10.2147/ijn.s156984. 
116. Hou, L.; Shi, Y.; Jiang, G.; Liu, W.; Han, H.; Feng, Q.; Zhang, Z. Smart nanocomposite hydrogels based on azo crosslinked graphene oxide for oral colon-specific drug delivery. Nanotechnol., 2016, 27, 315105. https://doi.org/10.1088/0957-4484/27/31/315105.

117. Zindani, D.; Kumar, K. Graphene-based polymeric nanocomposites: An introspection into functionalization, processing techniques and biomedical applications. Biointerface Res. Appl. Chem. 2019, 9, 3926-3933.

118. Nahorny, S.; Zanin, H.; Christino, V.A.; Marciano, F.R.; Lobo, A.O.; Soares, L.E.S. Multi-walled carbon nanotubes/graphene oxide hybrid and nanohydroxyapatite composite: A novel coating to prevent dentin erosion. Mater. Sci. Engin. C 2017, 79, 199-208, https://doi.org/10.1016/j.ultsonch.2018.02.016

119. Su, I.H.; Lee, C.F.; Su, Y.P.; Wang, L.H. Evaluating a cobalt-tetraphenyl porphyrin complex, functionalized with a reduced graphene oxide nanocomposite, for improved tooth whitening. J. Esth. Restor. Dent. 2016, 28, 321-329. https://doi.org/10.1111/jerd.12240.

120. Cucchi, A.; Ghensi, P. Vertical guided bone regeneration using Titanium-reinforced d-PTFE membrane and prehydrated corticocancellous bone graft. Open Dent. J. 2014, 8, 194-200. https://doi.org/10.2174/1874210601408010194.

121. Scantlebury, T.V. 1982-1992: A Decade of technology development for guided tissue regeneration. $J$. Periodontol. 1993, 64, 1129-1137. https://doi.org/10.1902/jop.1993.64.11s.1129.

122. De Marco, P.; Zara, S.; De Colli, M.; Radunovic, M.; Lazović, V.; Ettorre, V.; Fontana, A. Graphene oxide improves the biocompatibility of collagen membranes in an in vitro model of human primary gingival fibroblasts. Biomed. Mater. 2017, 12, 055005. https://doi.org/10.1088/1748-605x/aa7907.

123. Radunovic, M.; De Colli, M.; De Marco, P.; Di Nisio, C.; Fontana, A.; Piattelli, A.; Zara, S. Graphene oxide enrichment of collagen membranes improves DPSCs differentiation and controls inflammation occurrence. J. Biomed. Mater. Res. Part A. 2017, 105, 2312-2320. https://doi.org/10.1002/jbm.a.36085.

124. He, J.; Zhu, X.; Qi, Z.; Wang, L.; Aldalbahi, A.; Shi, J.; Tang, Z. The inhibition effect of graphene oxide nanosheets on the development of Streptococcus mutans biofilms. Particle Particle Syst. Charact. 2017, 34, 1700001. https://doi.org/10.1002/ppsc.201700001.

125. Zita Gomes, R.; de Vasconcelos, M. R.; Lopes Guerra, I. M.; de Almeida, R. A. B.; de Campos Felino, A. C. Implant Stability in the Posterior Maxilla: A Controlled Clinical Trial. BioMed. Res. Int. 2017, 1-11. https://doi.org/10.1155/2017/6825213.

126. Ren, N.; Li, J.;Qiu, J.; Yan, M.; Liu, H.; Ji, D.; Liu, H. Growth and accelerated differentiation of mesenchymal stem cells on graphene-oxide-coated titanate with dexamethasone on surface of titanium implants. Dent. Mater. 2017, 33, 525-535. https://doi.org/10.1016/j.dental.2017.03.001.

127. Guazzo, R.; Gardin, C.; Bellin, G.; Sbricoli, L.; Ferroni, L.; Ludovichetti, F.; Zavan. Graphene-based nanomaterials for tissue engineering in the dental field. Nanomater. 2018, 8, 349. https://doi.org/10.3390/nano8050349.

128. Park, C.; Park, S.; Lee, D.; Choi, K.S.; Lim, H.P.; Kim, J. Graphene as an enabling strategy for dental implant and tissue regeneration. Tissue Engin. Regen. Med. 2017, 14, 481-493. https://doi.org/10.1007/s13770-017-0052-3.

129. Jung, H.S.; Lee, T.; Kwon, I.K.; Kim, H.S.; Hahn, S.K.; Lee, C.S. Surface modification of multipass caliber-rolled Ti alloy with dexamethasone-loaded graphene for dental applications. ACS Appl. Mater. Interf. 2015, 7, 9598-9607. https://doi.org/10.1021/acsami.5b03431.

130. Qian, W.; Qiu, J.; Su, J.; Liu, X. Minocycline hydrochloride loaded on titanium by graphene oxide: An excellent antibacterial platform with the synergistic effect of contact-killing and release-killing. Biomater. Sci. 2018, 6, 304-313. https://doi.org/10.1039/c7bm00931c.

131. Jin, J.; Zhang, L.; Shi, M.; Zhang, Y.; Wang, Q. Ti-GO-Ag nanocomposite: The effect of content level on the antimicrobial activity and cytotoxicity. Int. J. Nanomed. 2017, 12, 4209-4224. https://doi.org/10.2147/ijn.s134843.

132. Zhou, Q.; Yang, P.; Li, X.; Liu, H.; Ge, S. Bioactivity of periodontal ligament stem cells on sodium titanate coated with graphene oxide. Sci. Rep. 2016, 6(1). https://doi.org/10.1038/srep19343.

133. Perreault, F.; Fonseca de Faria, A.; Elimelech, M. Environmental applications of graphene-based nanomaterials. Chem. Soc. Rev. 2015, 44, 5861-5896. https://doi.org/10.1039/c5cs00021a.

134. Ziyu, Ge.; Luming, Yang.; Fang, Xiao.; Yani, Wu.; Tingting, Yu.; Jing, Chen.; Jiexin, Lin.; Zhang, Y. Graphene family nanomaterials: Properties and potential applications in dentistry. Int. J. Biomater. 2018. https://doi.org/10.1155/2018/1539678.

135. Tahriri, M.; Del Monico, M.; Moghanian, A.; Yaraki, M. T.; Torres, R.; Yadegari, A.; Tayebi, L. Graphene and its derivatives: Opportunities and challenges in dentistry. Mater. Sci. Engin. C. 2019. https://doi.org/10.1016/j.msec.2019.04.051.

136. Akankshya, S.; Tasneem, B.; Alexander, S.; Jung, Y L. Graphene for dental implant applications. Adv. Dent. Oral Health. 2017, 4, 555-642 https://doi.org/10.19080/ADOH.2017.04.555642.

137. Xie, H.; Cao, T.; Rodríguez-Lozano, F.J.; Luong-Van, E.K.; Rosa, V. Graphene for the development of the next-generation of biocomposites for dental and medical applications. Dent. Mater. 2017, 33, 765-774. https://doi.org/10.1016/j.dental.2017.04.008. 
138. Corrêa, J. M.; Mori, M.; Sanches, H. L.; Cruz, A. D.; da, Poiate, E.; Poiate, I.A.V.P. Silver nanoparticles in dental biomaterials. Int. J. Biomater. 2015, 1-9. https://doi.org/10.1155/2015/485275.

139. Chudobova, D.; Nejdl, L.; Gumulec, J.; Krystofova, O.; Rodrigo, M.; Kynicky, J.; Kizek, R. Complexes of silver(i) ions and silver phosphate nanoparticles with hyaluronic acid and/or chitosan as promising antimicrobial agents for vascular grafts. Int. J. Mol. Sci. 2013, 14, 13592-13614. https://doi.org/10.3390/ijms140713592.

140. Steckiewicz, K.P.; Zwara, J.; Jaskiewicz, M.; Kowalski, S.; Kamysz, W.; Zaleska-Medynska, A.; Inkielewicz-Stepniak, I. Shape-depended biological properties of $\mathrm{Ag}_{3} \mathrm{PO}_{4}$ microparticles: evaluation of antimicrobial properties and cytotoxicity in in vitro model- safety assessment of potential clinical usage. Oxidat. Med. Cell. Long. 2019, 1-19. https://doi.org/10.1155/2019/6740325.

141. Hong, X.; Wu, X.; Zhang, Q.; Xiao, M.; Yang, G.; Qiu, M.; Han, G. Hydroxyapatite supported $\mathrm{Ag}_{3} \mathrm{PO}_{4}$ nanoparticles with higher visible light photocatalytic activity. Appl. Surf. Sci. 2012, 258, 4801-4805. https://doi.org/10.1016/j.apsusc.2012.01.102.

142. Chalal, S.; Haddadine, N.; Bouslah, N.; Benaboura, A. Preparation of poly(acrylic acid)/silver nanocomposite by simultaneous polymerization-reduction approach for antimicrobial application. J. Poly. Res. 2012, 19. https://doi.org/10.1007/s10965-012-0024-1.

143. Qian, W.; Qiu, J.; Su, J.; Liu, X. Minocycline hydrochloride loaded on titanium by graphene oxide: An excellent antibacterial platform with the synergistic effect of contact-killing and release-killing. Biomater. Sci. 2018, 6, 304-313. https://doi.org/10.1039/c7bm00931c.

144. Xu, D.; Wang, Q.; Yang, T.; Cao, J.; Lin, Q.; Yuan, Z.; Li, L. Polyethyleneimine capped silver nanoclusters as efficient antibacterial agents. Int. J. Environ. Res. Publ. Health. 2016, 13, 334. https://doi.org/10.3390/ijerph13030334.

145. Lee, H.J.; Lee, S.G.; Oh, E.J.; Chung, H.Y.; Han, S.I.; Kim, E.J.; Choi, J.H. Antimicrobial polyethyleneimine-silver nanoparticles in a stable colloidal dispersion. Collo. Surf. Biointerface 2011, 88, 505-511. https://doi.org/10.1016/j.colsurfb.2011.07.041.

146. Zhao, R.; Kong, W.; Sun, M.; Yang, Y.; Liu, W.; Lv, M.; Hao, R. Highly stable graphene-based nanocomposite (GO-PEI-Ag) with broad-spectrum, long-term antimicrobial activity and antibiofilm effects. ACS Appl. Mater. Interf. 2018, 10, 17617-17629. https://doi.org/10.1021/acsami.8b03185.

147. Ma, S.; Zhan, S.; Jia, Y.; Zhou, Q. Highly efficient antibacterial and Pb(II) removal effects of AgCoFe2O4-GO nanocomposite. ACS Appl. Mater. Interf. 2015, 7, 10576-10586. https://doi.org/10.1021/acsami.5b02209.

148. Peng, L.; Chang, L.; Liu, X.; Lin, J.; Liu, H.; Han, B.; Wang, S. Antibacterial property of a polyethylene glycol-grafted dental material. ACS Appl. Mater. Interf. 2017, 9, 17688-17692. https://doi.org/10.1021/acsami.7b05284.

149. Marshall, M.V.; Cancro, L.P.; Fischman, S.L. Hydrogen peroxide: A review of its use in dentistry. J. Periodontol. 1995, 66, 786-796. https://doi.org/10.1902/jop.1995.66.9.786.

150. Martha, C.; Anjelh-Baqiya, M.; Cahyono, Y.D. Synthesis and photoluminesence study of reduced graphene oxide (rGO)/ZnO for solar energy absorbing materials. IOP Conf. Ser. Mater. Sci. Engin. 2017, 196, 12-36. https://doi.org/10.1088/1757-899X/196/1/012036.

151. Benevidesa, A.P.; Camposb, A.R.; Vieirab, L.C.; Perezb, C.R.; Cesara, D.V. Reduced graphene oxide-zinc oxide flower-like composite for glass-ionomer materials reinforcement. Mat. Res. 2020, 23. https://doi.org/10.1590/1980-5373-mr-2019-0580.

152. Naskar, A.; Bera, S.; Bhattacharya, R.; Roy, S.S.; Jana, S. Solution based peg and pvp capped maghemitereduced graphene oxide nanocomposites: Cell viability study. Biointerface Res. Appl. Chem. 2018, 8, 3751-3757.

153. Liu, L.; Cai, R.; Wang, Y.; Tao, G.; Ai, L.; Wang, P.; He, H. Polydopamine-assisted silver nanoparticle self-assembly on sericin/agar film for potential wound dressing application. Int. J. Mol. Sci. 2018, 19, 2875. https://doi.org/10.3390/ijms19102875.

154. Cai, R.; Tao, G.; He, H.; Song, K.; Zuo, H.; Jiang, W.; Wang, Y. One-step synthesis of silver nanoparticles on polydopamine-coated sericin/polyvinyl alcohol composite films for potential antimicrobial applications. Mol. 2017, 2, 721. https://doi.org/10.3390/molecules22050721.

155. Soysal, F.; Çıplak, Z.; Getiren, B.; Gökalp, C.; Yıldız, N. Synthesis of GO-Fe3O4-PANI nanocomposite with excellent NIR absorption property. Collo. Surf. A: Physicochem. Engin. Asp. 2019, 578, 123623. https://doi.org/10.1016/j.colsurfa.2019.123623.

156. Konopka, K.; Goslinski, T. Photodynamic therapy in dentistry. J. Dent. Res. 2007, 86, 694-707. https://doi.org/10.1177/154405910708600803.

157. Ohk, S.H.; Hwang, H.S. Other applications of photo catalyst in dental treatments in diverse fields. Orthodont. Basic Asp. Clin. Consid. 2012. https://doi.org/10.5772/31029.

158. Yadav, D.; Upadhyay, S.K.; Anwar, M.F.; Unnithan, J.S. A review on the patents of various metal nanoparticles: Preparations and formulations. World J. Pharm. Pharmaceut. Sci. 2016, 5, 1309-1317.

159. Liu, L.; Xu, K.; Wang, H.; Jeremy Tan, P.K.; Fan, W.; Venkatraman, S.S.; Yang, Y.Y. Self-assembled cationic peptide nanoparticles as an efficient antimicrobial agent. Nature Nanotechnol. 2009, 4, 457-463. https://doi.org/10.1038/nnano.2009.153. 
160. Debbarma, J.; Mandal, P.; Saha, M. Chemistry and mechanism of one-step formation of graphene from agrowaste. Lett. Appl. Nanosci. 2020, 9, 1389-1394 https://doi.org/10.33263/LIANBS93.13891394

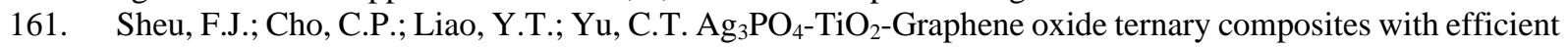
photodegradation, hydrogen evolution, and antibacterial properties. Catalyst. 2018, 8, 57. https://doi.org/10.3390/catal8020057

162. He, H.; Jiang, Z.; He, Z.; Liu, T.; Li, E.; Li, B.W. Photocatalytic activity of attapulgite-TiO2- $\mathrm{Ag}_{3} \mathrm{PO}_{4}$ ternary nanocomposite for degradation of Rhodamine B under simulated solar irradiation. Nanoscale Res. Lett. 2018, 13, 28. https://doi.org/10.1186/s11671-018-2443-3.

163. Wang, L.; Hu, C.; Shao, L. The antimicrobial activity of nanoparticles: present situation and prospects for the future. Int. J. Nanomed. 2017, 12, 1227-1249. https://doi.org/10.2147/IJN.S121956.

164. Burdusel, A.C.; Gherasim, O.; Grumezescu, A.M.; Mogoanta, L.; Ficai, A.; Andronescu, E. Biomedical applications of silver nanoparticles: An up-to-date overview. Nanomater. (Basel.). 2018, 8, 681. https://doi.org/10.3390/nano8090681.

165. Fathi-Achachelouei, M.; Knopf-Marques' H.; Ribeiro da Silva, C.E.; Barthès, J.; Bat, E.; Texcaner, A.; Vrana, N.E. Use of nanoparticles in tissue engineering and regenerative medicine. Front. Bioeng. Biotechnol. 2019, https://doi.org/10.3389/fbioe.2019.00113.

166. Pardo, J.; Peng, z.; Leblanc, R.M. Cancer targeting and drug delivery using carbon-based quantum dots and nanotubes. Mol. 2018, 23, 378. https://doi.org/10.3390/molecules23020378.

167. Nifontova, G.; Ramos-Gomes, F.; Alves, F.; Nabiev, I.; Sukhanova, A. Cancer cell targeting with functionalized quantum dot-encoded polyelectrolyte microcapsules. Front. Chem. 2019, https://doi.org/10.3389/fchem.2019.00034.

168. Montane, X.; Bajek, A.; Roszkowski, K.; Montornes, J.M.; Giamberini, M.; Roszowski, S.; Kowalczyk, O.; Gracia-Valls, R.; Tylkowski, B. Encapsulation for cancer therapy. Mol. 2020, 25, 1605. https://doi.org/10.3390/molecules25071605

169. Molaei, M.J. Carbon quantum dots and their biomedical and therapeutic applications: A review. RSC Adv. 2019, 9, 6460. https://doi.org/10.1039/c8ra08088g. 